\title{
IL-23 activates innate lymphoid cells to promote neonatal intestinal pathology
}

L Chen $^{1,8}, \mathrm{Z} \mathrm{He}^{1,8}$, E Slinger ${ }^{1}$, G Bongers $^{1}$, TLS Lapenda ${ }^{1}$, ME Pacer $^{1}$, J Jiao ${ }^{1}$, MF Beltrao ${ }^{1}$, AJ Soto ${ }^{1}$, $\mathrm{N} \mathrm{Harpaz}^{2}$, RE Gordon ${ }^{2}$, JC Ochando ${ }^{1,3}$, M Oukka $^{4}$, AC Iuga ${ }^{5}$, SW Chensue ${ }^{6,7}$, JM Blander ${ }^{1}$, GC Furtado ${ }^{1}$ and SA Lira ${ }^{1}$

Interleukin-23 (IL-23) responsive group 3 innate lymphoid cells (ILC3s) have been implicated in immune homeostasis and pathogenesis in the adult, but little is known about their roles in the newborn. Here we show that IL-23 promotes conversion of embryonic intestinal Lin ${ }^{-}$IL-23R ${ }^{+}$Thy $1^{+}$cells into IL-22-producing Thy $1^{+}$Sca- ${ }^{\text {hi }}$ ILC3s in vitro. Gutspecific expression of IL-23 also activated and expanded Thy $1^{+}$Sca- $1^{\text {hi }}$ ILC3s, which produced IL-22, IL-17, interferon gamma (IFN- $\gamma$ ), and granulocyte-macrophage colony-stimulating factor (GM-CSF) and were distinct from canonical $\mathrm{CD}^{+}$lymphoid tissue inducer (LTi) cells. These ILC3s accumulated under the epithelium in intercellular adhesion molecule (ICAM)-1-positive cell aggregates together with neutrophils that disrupted the epithelium, leading to the formation of discrete intestinal erosions, bleeding, and neonatal death. Genetic and antibody depletion of ILC3s rescued the mice from neonatal death. Antibiotic treatment of pregnant mothers and offspring prolonged survival of IL-23 transgenic mice, suggesting a role for the commensal flora on ILC3-induced pathogenesis. Our results reveal a novel role for the IL-23-ILC3s axis in the pathogenesis of neonatal intestinal inflammation.

\section{INTRODUCTION}

Interleukin-23 (IL-23) is a heterodimeric cytokine formed by the IL-23-specific p19 subunit and the IL-12p40 subunit. ${ }^{1}$ IL-23 plays a pivotal role in adult intestinal inflammation. ${ }^{2}$ Recent evidence suggests that IL-23 acts as a molecular switch to promote pathological $\mathrm{T}$ cell and innate lymphoid cell (ILC) responses in murine models of colitis and in human inflammatory bowel disease. ${ }^{3-9}$

ILCs regulate immunity, inflammation, tissue repair and remodeling in multiple anatomical compartments, particularly at mucosal surfaces. ${ }^{10}$ ILCs are currently categorized into three distinct populations based on their developmental requirements for defined transcription factors, expression of cell surface markers, and secretion of specific cytokines. ${ }^{11-13}$ IL-23 has been implicated in the activation and induction of group 3 ILCs (ILC3s). ${ }^{13}$ ILC3s depend on the transcription factor RARrelated orphan receptor gamma $(\mathrm{ROR} \gamma) \mathrm{t}$ and are also called
$\mathrm{ROR} \gamma \mathrm{t}^{+}$ILCs. ILC3s can be further categorized into several subsets with distinct but overlapping phenotypic and functional markers. Lymphoid tissue inducer (LTi) cells represent the subset of ILC3s responsible for the formation of secondary lymphoid organs during embryogenesis. ${ }^{14,15}$ Intestinal LTi cells do not generally express lineage-specific markers but can express the T-cell surface molecule CD4. ${ }^{16,17}$ Two other subsets of ILC3s are defined by their expression of natural cytotoxicity receptors (NCRs, including NKp46 and NKp44) and are thus categorized into $\mathrm{NCR}^{+}$ILC3s and $\mathrm{NCR}^{-}$ILC3s. $^{12,13} \mathrm{NCR}^{+}$ ILC3s also play a role in gut-associated lymphoid tissue generation, ${ }^{18,19}$ and appear to be essential for host-protective immunity in the intestine. ${ }^{20}$ The development/maintenance of $\mathrm{NCR}^{+}$ILC3s, different from LTi cells, appears to be dependent of commensal-derived signals. ${ }^{21-23}$ Another subset within the ILC3s was found to mediate pathology in a mouse model of innate colitis. ${ }^{4}$ These colitogenic $\mathrm{NCR}^{-}$ILC3s lack expression

\footnotetext{
${ }^{1}$ Immunology Institute, Icahn School of Medicine at Mount Sinai, New York, New York, USA. ²Department of Pathology, Icahn School of Medicine at Mount Sinai, New York, New York, USA. ${ }^{3}$ Department of Nephrology, Icahn School of Medicine at Mount Sinai, New York, New York, USA. ${ }^{4}$ Department of Pediatrics, University of Washington, Seattle, Washington, USA. ${ }^{5}$ Department of Pathology and Cell Biology, Columbia University Medical Center, New York, New York, USA. ${ }^{6}$ Department of Pathology, University of Michigan Medical School, Ann Arbor, Michigan, USA and ${ }^{7}$ Section of Pathology and Laboratory Medicine, Veterans Affairs Ann Arbor Healthcare System, Ann Arbor, Michigan, USA. Correspondence: SA Lira (sergio.lira@mssm.edu)

${ }^{8}$ The first two authors contributed equally to this work.
} 
of NKp46 and do express thymocyte differentiation antigen 1 (Thy1), stem cell antigen 1 (Sca-1), and IL-23 receptor (IL-23R) and secrete both interferon gamma (IFN- $\gamma$ ) and IL-17 in addition to IL-22 under IL-23 stimulation. ${ }^{4}$ These $\mathrm{NCR}^{-}{ }^{-}$ILC3s accumulate in the inflamed colon and are directly responsible for the chronic pathology.

While it is established that IL-23 affects both the maintenance of a Thelper 17 response ${ }^{3,8}$ and activation and function of ILC3s in adults, ${ }^{12}$ little is known about its role in early development. It is generally accepted that the immune system is immature at birth because the structure of bone marrow, spleen, and lymphoid nodes is not fully defined, there are few B and $\mathrm{T}$ cells in circulation and in the periphery, and there are no memory B and T cells. ${ }^{24-26}$ However, some aspects of the immune response are already in place. For instance, human neonatal dendritic cells (DCs), respond to Toll-like receptor stimulation by secreting large amounts of IL-23. ${ }^{27-29}$ Human neonatal DC-derived IL-23 promotes the differentiation of neonatal $\mathrm{CD}^{+} \mathrm{T}$ cells into IL-17-producing cells. ${ }^{30}$ In addition, human neonatal DC-derived IL-23 combined with specific TCR signaling drives the generation of neonatal $\gamma \delta \mathrm{T}$ cells equipped with a range of cytotoxic mediators and distinct subpopulations producing IFN- $\gamma$ and IL- $17 .{ }^{25}$ Isolated DCs from neonatal mice are able to produce relatively higher levels of IL-23p40, but lower levels of IL-12p70 than their DC counterparts in adult mice. ${ }^{31,32}$

Here we show that IL-23 promotes differentiation of embryonic Thyl ${ }^{+} \mathrm{IL}^{2} 23 \mathrm{R}^{+}$intestinal cells into $\mathrm{Thy} 1^{+} \mathrm{Sca}-$ $1^{\text {hi }}$ ILC3s in vitro. Gut-specific expression of IL-23 in transgenic mice promoted significant expansion of a subset of ILC3s that together with neutrophils and the intestinal flora promoted development of erosive lesions, bleeding, and neonatal death. These results indicate that increased IL-23 expression can promote development of pathogenic ILC3s in the newborn intestine.

\section{RESULTS}

IL-23 activates embryonic IL-23R ${ }^{+}$Thy $1^{+}$cells to become IL-22-producing ROR $\gamma^{+}{ }^{+}$Thy ${ }^{+}$Sca- ${ }^{\text {hi }}$ cells in vitro

While a role for IL-23 in regulating immune homeostasis and pathogenesis in the adult is firmly established, ${ }^{3,13}$ its role in the prenatal/neonatal immune regulation is poorly understood. To start studying the role of IL-23 in this period, we examined the distribution of IL-23-responsive cells in the intestine. IL-23 interacts with cells that co-express the IL-23R subunit and the shared IL-12R $\beta 1$ chain. ${ }^{33}$ We took advantage of IL-23R green fluorescent protein (GFP) reporter mice ${ }^{34}$ to determine which cells expressed IL-23R. Most ( 70\%) CD45 ${ }^{+}$IL-23RGFP $^{+}$ cells in the gut of prenatal mice were lineage-negative $\left(\mathrm{Lin}^{-}\right)$ cells. The remaining cells were $\mathrm{CD} 11 \mathrm{~b}^{+}(\sim 18 \%)$ and $\mathrm{CD} 11 \mathrm{c}^{+}$ $(\sim 12 \%)$ (Supplementary Figure $\mathrm{S1}$ online). Most $\mathrm{Lin}^{-}$ $\mathrm{IL}^{2} 23 \mathrm{RGFP}^{+}$cells $(80 \%)$ were $\mathrm{Thy}{ }^{+}{ }^{+} \mathrm{Sca}-1^{-}$cells in the intestine of Il-23r $r^{+/ g f P}$ mice at embryonic day E18.5 (Figure 1a). Culture of embryonic leukocytes from the $\mathrm{Il}-23 r^{+/+}$intestine with recombinant IL-23 promoted development of Lin $^{-}$ Thy $1^{+}$Sca- $1^{\text {hi }}$ cells (Figure 1b). Incubation of intestinal cells from IL-23R-deficient (Il-23rofp/gfp) embryos with IL-23, as expected, did not result in the appearance of Lin ${ }^{-}$Thy $1^{+}$Sca- ${ }^{\text {hi }}$ cells (Figure 1b). Further characterization of this IL-23-stimulated Lin ${ }^{-}$Thy ${ }^{+}$Sca- $1^{\text {hi }}$ cell population showed that they were negative for CD4, NKp46, and CCR6 (Supplementary Figure S2). Adult IL-23-responsive cells produce IL-17 and/or IL-22 when challenged with IL-23. ${ }^{13}$ Lin ${ }^{-}$Thy $1^{+}$Sca- ${ }^{\text {hi }}$ cells generated in vitro after stimulation with IL-23 produced IL-22 (Figure 1c), but not IL-17.

To further confirm that IL-23 acted directly on the Lin ${ }^{-}$ Thy ${ }^{+}$cells, we sorted Lin ${ }^{-}$Thy $1^{+}$and Lin ${ }^{-}$Thy ${ }^{-}$cells from the intestine of embryonic wild-type (WT) mice and cultured them in the presence of IL-23 or vehicle. We found that the Lin ${ }^{-}$Thy $^{+}$cells converted to Lin ${ }^{-}$Thy ${ }^{+}$Sca- ${ }^{\text {hi }}$ cells after IL-23 stimulation (Figure 1d). As $\mathrm{CD}^{-}{ }^{-} \mathrm{CD} 4{ }^{+}$LTi cells are also Thy $1^{+},{ }^{13}$ we asked next whether Lin $^{-}$Thy $1^{+}$ $\mathrm{IL}^{2} 23 \mathrm{R}^{+} \mathrm{CD} 4^{-}$cells could respond to IL-23. We sorted $\mathrm{Lin}^{-}$Thy $1^{+} \mathrm{IL}-23 \mathrm{R}^{+} \mathrm{CD} 4^{-}$cells from the intestine of Il-23r ${ }^{+/ g f P}$ mice and challenged them with IL-23. We found that more than $90 \%$ of the $\mathrm{Lin}^{-} \mathrm{Thy} 1^{+} \mathrm{IL}^{-23 \mathrm{R}^{+} \mathrm{CD} 4}{ }^{-}$cells became Lin ${ }^{-}$Thy $^{+}{ }^{+}$Sca- ${ }^{\text {hi }}$ cells (Figure 1e).

To further gain insight into how IL-23 promoted the development of Lin ${ }^{-}$Thy $1^{+}$Sca- ${ }^{\text {hi }}$ cells, we examined expression of ROR $\gamma \mathrm{t}$ and IL-22. Treatment of the Lin ${ }^{-}$Thy ${ }^{+}$

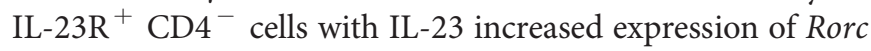
(Figure 1f) and Il-22 (Figure 1f, g). Incubation of intestinal cells from ROR $\gamma \mathrm{t}$-deficient embryos with IL-23, as expected, did not result in the appearance of Lin ${ }^{-}$Thy $1^{+}$Sca- ${ }^{\text {hi }}$ cells (Supplementary Figure S3), suggesting that ROR $\gamma$ t is critical for $\mathrm{Lin}^{-} \mathrm{Thyl}^{+} \mathrm{Sca}-1^{\text {hi }}$ cells development. Together, these results indicate that IL-23 activates embryonic $\mathrm{Lin}^{-} \mathrm{IL}-$ $23 \mathrm{R}^{+} \mathrm{Thyl}^{+}$cells to become IL-22-producing $\mathrm{ROR} \gamma \mathrm{t}^{+}$ Thy $1^{+}$Sca- $1^{\text {hi }}$ ILC3s in vitro.

\section{Transgenic expression of IL-23 in the neonatal intestine causes erosive lesions, bleeding, and neonatal death}

To study if IL-23 had a role in the activation of ILC3s in the intestine, we generated IL-23 transgenic mice. To do so, we first developed sets of mice expressing IL-23p19 (V19 mice) and IL-23p40 ( $V 40$ mice) from the villin promoter, which targets expression of transgenes to the intestinal epithelium. ${ }^{35} \mathrm{~V} 19$ and V40 mice were then intercrossed to generate V23 mice (Figure 2a). Surprisingly, no V23 transgenic mice were found alive at postnatal day 8 (P8) (Figure 2b), suggesting early mortality. Further genotypic analysis showed that V23 mice survived gestation but died at P0-P1 (Figure 2b). To confirm transgene expression, we performed enzyme-linked immunosorbent assay in gut extracts and found that IL-23 levels were approximately sevenfold higher in the intestine of transgenic mice than controls (Supplementary Figure S4). These levels are comparable with those induced by administration of CD40specific antibodies to activate IL-23 expression in $\mathrm{Rag}^{-1-}$ mice. $^{36}$

Further examination of abdominal organs revealed that the small intestine (SI) was prominently affected in the transgenic mice (Figure 2c). On gross examination, the V23 mice had 
a

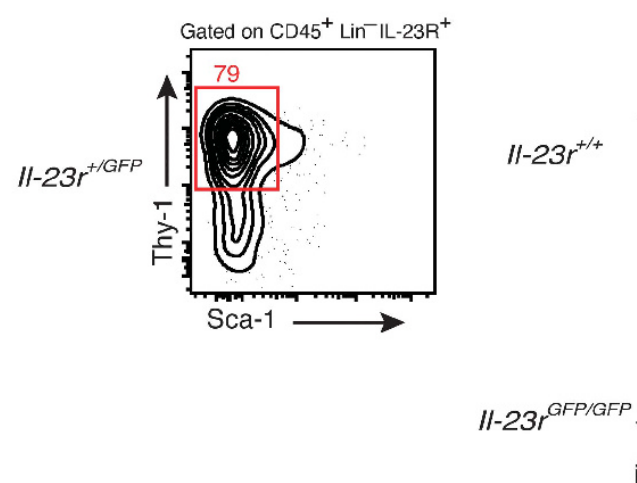

b
Gated on $\mathrm{CD}^{2} 5^{+} \mathrm{Lin}^{-}$

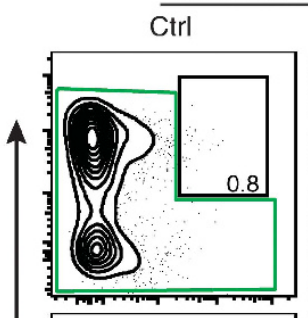

IL-23
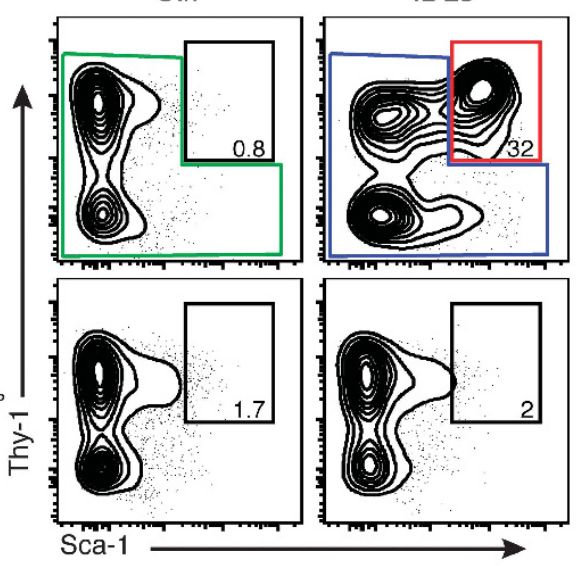

C

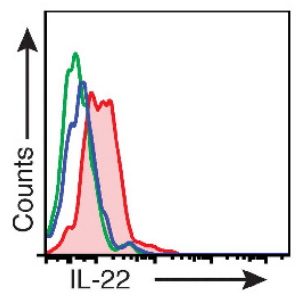

d
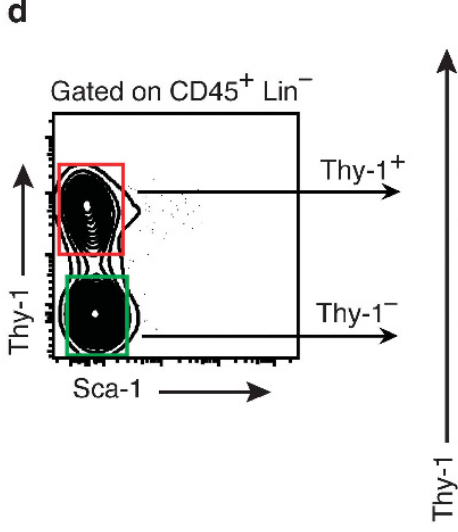

Ctrl
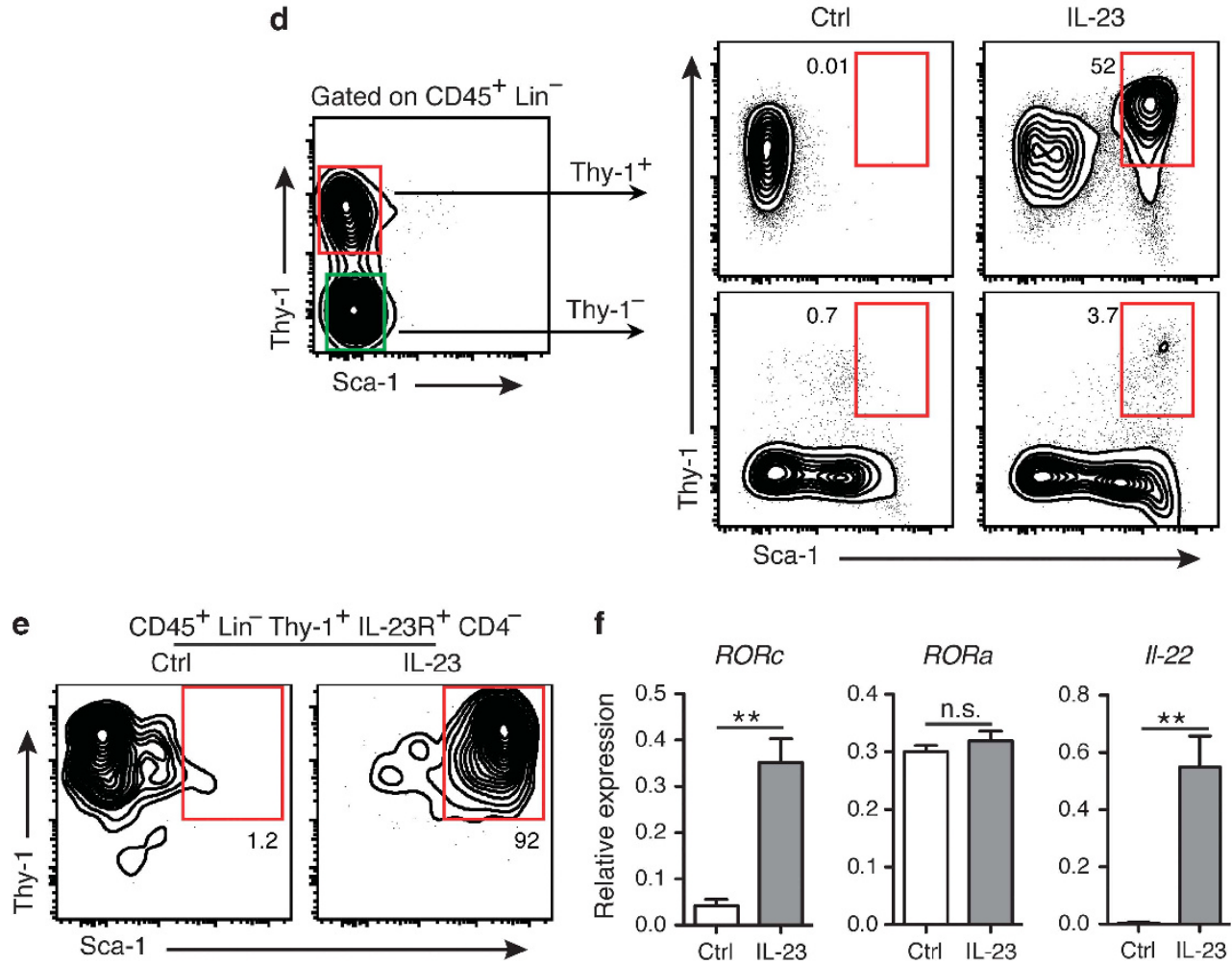

f
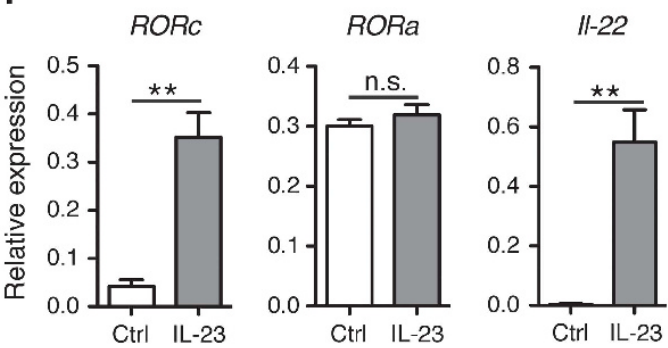

g

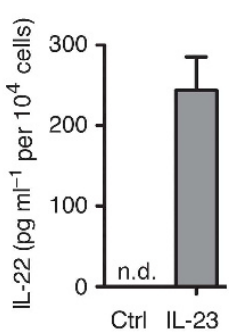

Figure 1 Interleukin-23 (IL-23) promotes development of Thy $1^{+}$Sca-1 $1^{\text {hi }}$ ILCs in vitro. (a) Flow cytometric analysis of thymocyte differentiation antigen 1 (Thy1) and stem cell antigen 1 (Sca-1) expression of gated CD45 ${ }^{+} \mathrm{Lin}^{-} \mathrm{IL}-23 \mathrm{R}^{+}$cells from the intestine of $I I-23 r^{+/ G F P}$ mice at embryonic day E18.5. (b) In vitro-stimulated $\mathrm{CD} 45^{+} \mathrm{Lin}^{-}$leukocyte subpopulations from the intestine of $1 /-23 r^{+/+}$and II-23rGFP/GFP mice at embryonic day E18.5 with IL-23 $\left(10 \mathrm{ng} \mathrm{ml}^{-1}\right.$ ) or vehicle (Ctrl) for $72 \mathrm{~h}$. Representative flow cytometry plots showing CD $45^{+} \mathrm{Lin}^{-}$Thy $1^{+}$Sca- $1^{\text {hi }}$ population after culture. (c) Intracellular cytokine stain of IL-22 expression by the populations shown in $\mathbf{b}$, colors correspond to the populations analyzed. (d) Culture of sorted Lin ${ }^{-}$Thy $1^{+}$and Lin ${ }^{-}$Thy $1^{-}$cells from the wild-type intestine at embryonic day E18.5 respond to IL-23 $\left(10 \mathrm{ng} \mathrm{ml}^{-1}\right.$ ) or vehicle (Ctrl) stimulation after $72 \mathrm{~h}$. Representative flow cytometry plots showing CD $45^{+} \mathrm{Lin}^{-}$Thy $1^{+}$Sca- $1^{\text {hi }}$ population after culture. (e) Representative flow cytometry plots showing sorted Lin ${ }^{-}$Thy $1^{+}$IL$23 \mathrm{R}^{+} \mathrm{CD} 4^{-}$cells from the intestine of $1 /-23 \mathrm{r}^{+/ G F P}$ mice at embryonic day E18.5 respond to IL-23 $\left(10 \mathrm{ng} \mathrm{ml}^{-1}\right)$ or vehicle (Ctrl) stimulation after $72 \mathrm{~h}$. (f)

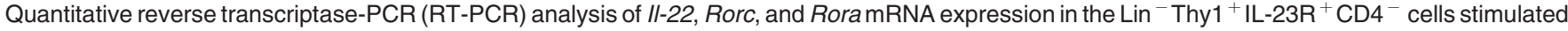
with vehicle (Ctrl) or IL-23. NS, not significant. ${ }^{*} P<0.01$. (g) Enzyme-linked immunosorbent assay (ELISA) evaluation of IL-22 in the culture supernatant of the Lin ${ }^{-}$Thy $1^{+}$IL-23R ${ }^{+}$CD $4{ }^{-}$cells stimulated with vehicle (Ctrl) or IL-23. Data are shown as means \pm s.e.m., $n=3-5$ per group. ND, not detectable. Results are representative of three independent experiments.

congested and dilated small bowels compared with littermate WT control mice (Figure 2c). Histologically, the general architecture of the intestine was preserved, but the lumen appeared distended and showed hemorrhage (Figure 2c). The most distinguished finding was the presence of discrete epithelial lesions overlying lamina propria lymphoid aggregates 
a

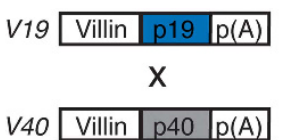

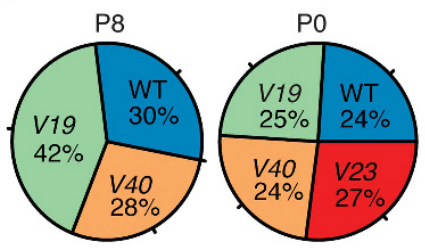

C

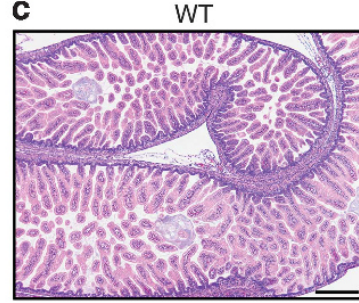

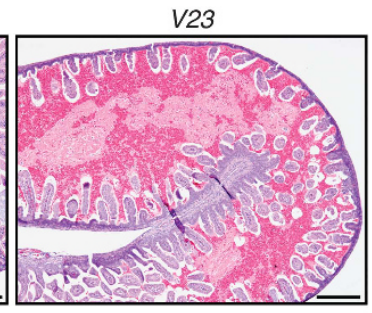

d

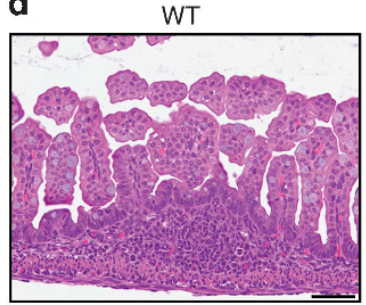

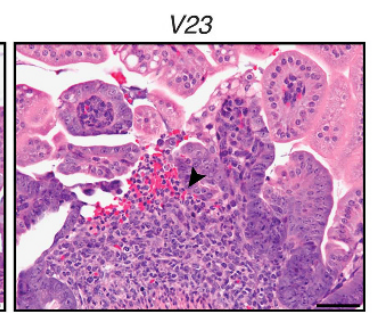

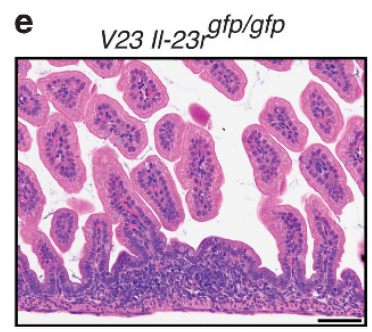

f

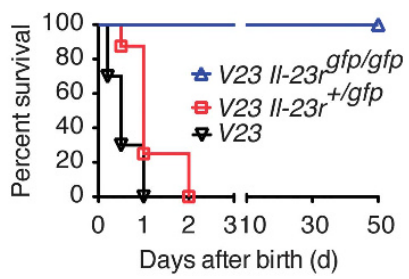

Figure 2 Transgenic expression of interleukin-23 (IL-23) in the intestine causes formation of erosive lesions, bleeding, and neonatal death. (a) Scheme for generation of V23mice. Independent sets of murine villin promoter $(9 \mathrm{~kb})$-driven transgenes encoding IL-23p19 or p40 were used to generate $V 19$ and V4O mice, respectively. (b) Genotypic ratios of wild-type (WT), V19, V40, and V23 mice at different ages postnatal day 0 (P0) ( $n=97)$ and postnatal day 8 (P8) $(n=69)$. (c, d) Representative hematoxylin and eosin (H\&E)-stained sections of the small intestine of WT and V23 mice at P0. Bar $=250 \mu \mathrm{m}$ in c and $50 \mu \mathrm{m}$ in d. Arrow indicates an erosive lesion. (e) Representative H\&E-stained section of the small intestine of $V 23 / I-23 r^{G F P / G F P}$ mice at P0. Bar $=50 \mu \mathrm{m}$. (f) The survival curves of $V 23(n=16), V 23 \| 1-23 r^{+/ G F P}(n=15)$, and V23 II-23r $r^{G F P / G F P}(n=18)$ mice. $P<0.001$ between $V 23 \|-23 r^{G F P / G F P}$ and $V 23$ mice by Log-rank test. Results are representative of three independent experiments.

(Figure 2d). The lesions consisted of disrupted epithelium in association with intraepithelial and superficial subepithelial neutrophilic infiltrates (Figure 2d). Neutrophils were also seen in the intestinal lumen, at the sites of epithelial disruption (Figure 2d). Scattered epithelial apoptotic bodies and reactive/ regenerative epithelial changes were also seen at the site of the lesions (Figure 2c, d).

To further ascertain that the biology observed was dependent on IL-23, and to rule out the possibility that the early lethality in the V23 mice could be a consequence of a non-specific effect caused by expression of two independent transgenes (Figure 2a, b), we intercrossed the V19 and V40 to mice deficient in the IL-23R $\left(\mathrm{Il}-23 r^{G F P / G F P}\right)$ to generate $\mathrm{V} 23 \mathrm{Il}$ $23 r^{G F P / G F P}$ mice. Similar to V23 mice, V23 Il-23r ${ }^{+/ G F P}$ mice succumbed immediately after birth. In great contrast, $\mathrm{V} 23 \mathrm{Il}$ $23 r^{G F P / G F P}$ mice survived to adulthood and did not show any signs of disease (Figure 2e, f). These results indicate that the phenotype observed in the V23 mice is directly elicited by the interaction of IL-23 with its receptor, and not the consequence of a spurious artifact induced by expression of the transgenes.

\section{IL-23 expression drives expansion of intestinal Lin ${ }^{-}$Thy $1^{+}$Sca- ${ }^{\text {hi }}$ cells in mice}

Next we asked whether transgenic expression of IL-23 in vivo affected development of $\mathrm{Lin}^{-} \mathrm{Thyl}^{+}{ }^{+} \mathrm{Sca}-1^{\text {hi }}$ ILCs in the neonatal intestine. First, we examined the frequency of $\mathrm{Lin}^{-}$ Thy $1^{+}$Sca- $1^{\text {hi }}$ population in the different organs of V23 transgenic mice at P0. IL-23-responsive $\mathrm{Lin}^{-} \mathrm{Thyl}^{+}{ }^{+} \mathrm{Sca}-1^{\text {hi }}$ cells were most abundant in the SI, representing $40-50 \%$ of all $\mathrm{Lin}^{-}$population, but were also present in the large intestine, mesenteric lymph nodes, and at lower frequency in the spleen (Figure 3a). In contrast, no Lin ${ }^{-} \mathrm{Thy} 1^{+} \mathrm{Sca}-1^{\text {hi }}$ cells were detected in the intestine, mesenteric lymph nodes or spleen of WT mice (Figure 3a). The total number of $\mathrm{Lin}^{-} \mathrm{Thyl}^{+} \mathrm{Sca}-1^{\text {hi }}$ cells in the SI of transgenic mice was dramatically increased compared with that of WT mice (Figure 3b).

At birth, the relative and absolute number of leukocytes $\left(\mathrm{CD} 45^{+}\right.$cells) in the SI V23 mice was increased (Figure 3c). The most increased leukocytes in $\mathrm{Lin}^{+}$population were $\mathrm{CD} 1 \mathrm{~b}^{+}$cells (Figure 3d, e). The dominant population among the $\mathrm{CD}_{11 \mathrm{~b}}{ }^{+}$cells were neutrophils $\left(\mathrm{CD} 11 \mathrm{~b}^{+} \mathrm{MHCII}^{-} \mathrm{Gr}-1^{+}\right.$ cells), whose numbers were markedly increased in the intestine of V23 mice compared with WT mice (Figure 3f). Further analyses showed that there were no changes in the relative number of most leukocytes (Figure 3d), with only modest increases in the absolute number of $\mathrm{CD}^{+}$cells, $\mathrm{B} 220^{+}$cells, and $\mathrm{CD} 11 \mathrm{c}^{+}$cells in $V 23$ mice compared with WT mice (Figure 3e). As expected, Thy ${ }^{+} \mathrm{Sca}-1^{\text {hi }}$ cells were the most abundant $\mathrm{Lin}^{-}$cells (Figure 3b, d, e). Other CD45 ${ }^{+} \mathrm{Lin}^{-}$cells such as the canonical intestinal LTi cells $\left(\mathrm{Lin}^{-} \mathrm{CD} 4^{+}\right)$were decreased in V23 mice compared with WT mice (Figure 3g). In addition, no NKp $46^{+}$ILC3s were detected in transgenic nor WT mice at this stage, consistent with the fact that NKp46 ${ }^{+}$ILC3s develop several days after birth and are normally induced by the intestinal commensal flora. ${ }^{21,23}$

Together these results indicate that IL-23 expression promoted the expansion of a distinct set of Thy $1^{+} \mathrm{Sca}-1^{\text {hi }}$ ILCs and increased in the numbers of neutrophils in the SI of V23 neonates.

\section{Lin ${ }^{-}$Thy $1^{+}$Sca- ${ }^{\text {hi }}$ cells present in the intestine of the V23} mice are NCR ${ }^{-}$ILC3s

To characterize the $\mathrm{Lin}^{-}$Thy $1^{+} \mathrm{Sca}-1^{\text {hi }}$ cells further, we examined expression of surface markers, transcription factors, 

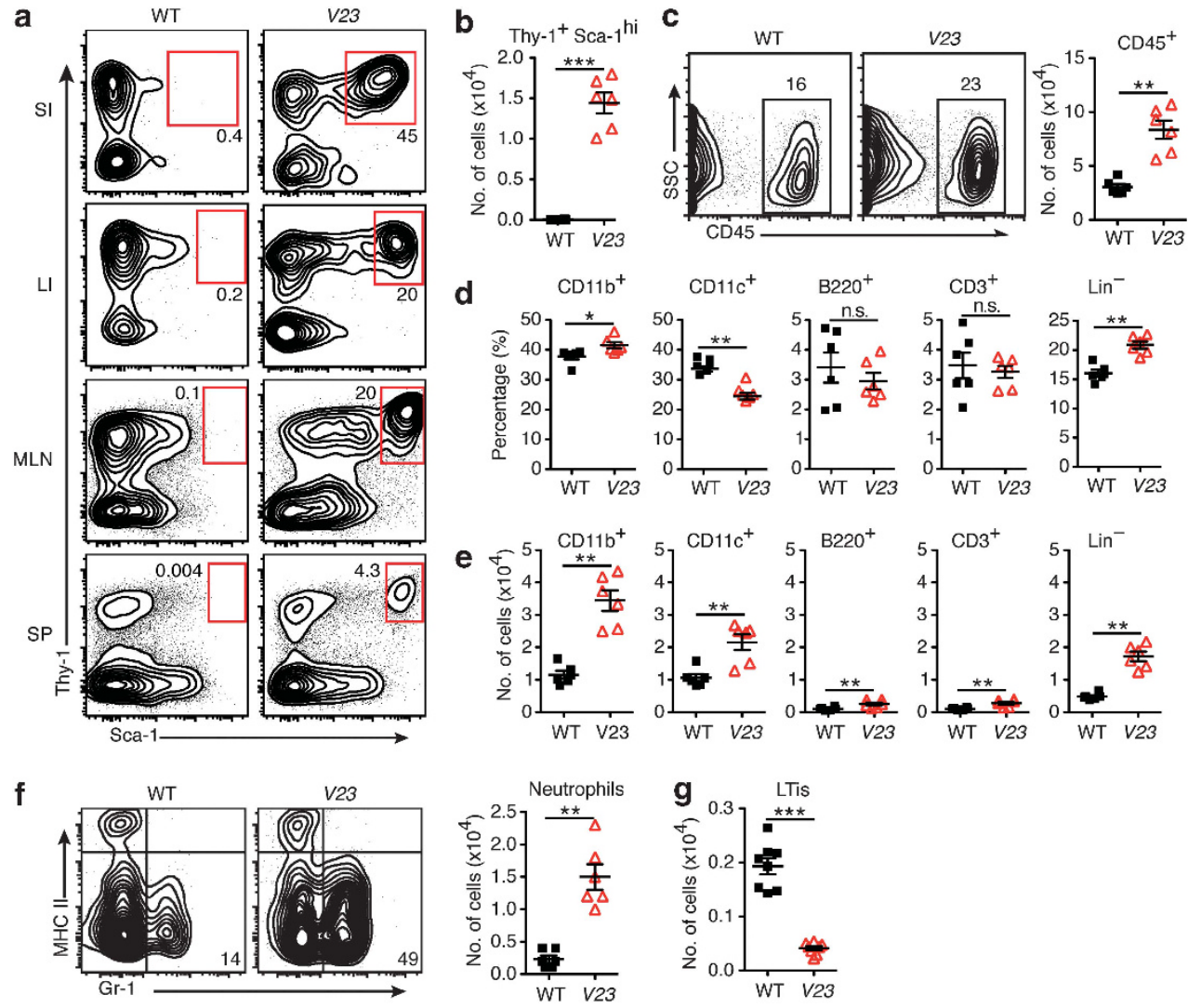

Figure 3 Gut-specific expression of interleukin-23 (IL-23) activates and expands Thy $1^{+}$Sca- $1^{\text {hi }}$ ILC3s in the neonatal intestine. (a) Relative number of Lin ${ }^{-}$Thy $1^{+}$Sca- ${ }^{\text {hi }}$ cells in small intestine (SI), large intestine (LI), mesenteric lymph nodes (MLNs), and spleen (SP) of wild-type (WT) and V23 mice at P0. Representative flow cytometry plots gated on CD45 ${ }^{+} \mathrm{Lin}^{-}$. (b) Absolute number of $\mathrm{Lin}^{-}$Thy $1^{+}$Sca- $1^{\text {hi }}$ cells in the SI of WT and V23 mice at postnatal day 0 (P0). Means \pm s.e.m., $n=5-6$ per group, ${ }^{* * *} P<0.001$. (c) Relative (left) and absolute (right) number of CD $45^{+}$cells in the SI of WT and $V 23$ mice at P0. Dot plots show cells gated on live cells. Means \pm s.e.m., $n=5-6$ per group, ${ }^{* \star} P<0.01$. (d, e) Relative (d) and absolute (e) number of CD11b ${ }^{+}$,

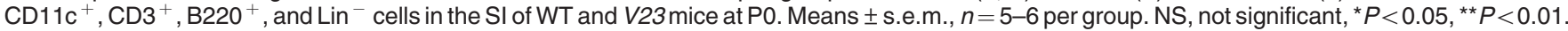
(f) Relative (left) and absolute (right) number of $\mathrm{CD} 45^{+} \mathrm{CD} 11 \mathrm{~b}^{+} \mathrm{MHClI}^{-} \mathrm{Gr}-1^{+}$cells in the SI of WT and V23 mice at P0. Dot plots show cells gated on $\mathrm{CD} 45^{+} \mathrm{CD} 11 \mathrm{~b}^{+}$. Means \pm s.e.m., $n=5-6$ per group, ${ }^{\star \star} P<0.01$. (g) Absolute number of lymphoid tissue inducer (LTi) cells (Lin ${ }^{-} \mathrm{CD} 4{ }^{+}$) in the SI of WT and V23 mice at P0. Means \pm s.e.m., $n=7-8$ per group, ${ }^{* * *} P<0.001$. Data are representative of three independent experiments.

and cytokines by flow cytometry. The Lin ${ }^{-}$Thy $1^{+}$Sca- $1^{\text {hi }}$ cells present in the neonatal SI of V23 mice co-expressed markers normally associated with ILC3s, such as IL-23R, ROR $\gamma \mathrm{t}$, IL-7R (CD127), CD44, CD25, c-Kit (CD117), and CCR6 (Figure 4a). Lin $^{-}$Thy $1^{+}$Sca- ${ }^{\text {hi }}$ cells did not express CD4 or NKp46 (Figure 4a) but did express high levels of Sca-1, which suggests that they were phenotypically distinct from LTi cells and NKp $46^{+}$ILC3s. ${ }^{12,13}$ Further phenotypic analysis showed that IL-18R and cytotoxic T-lymphocyte antigen 4 were expressed in Lin ${ }^{-}$Thy ${ }^{+}{ }^{+}$Sca- ${ }^{\text {hi }}$ cells (Figure 4a). Interestingly, cytotoxic T-lymphocyte antigen 4 was expressed by Lin $^{-}$Thyl $^{+}$Sca- ${ }^{\text {hi }}$ cells but not by classical LTi cells (Figure 4a). Similar to human LTi-like ILCs, ${ }^{37}$ Lin $^{-}$Thy $1^{+}$Sca- $1^{\text {hi }}$ cells expressed Toll-like receptor2 (Figure 4a).

IL-22, IL-17, and IFN- $\gamma$ are produced not only by $\mathrm{Lin}^{+}$cells, such as Th17 cells and $\gamma \delta \mathrm{T}$ cells, but also by mucosal ILCs. Intracellular flow cytometry revealed that neonatal CD $45^{+}$ $\mathrm{Lin}^{-}$cells, but not Lin ${ }^{+}$cells, produced most of IL-22, IL-17, IFN- $\gamma$, and granulocyte-macrophage colony-stimulating factor (GM-CSF) in the intestine of V23 mice (Figure $4 \mathbf{b}$ ), which is consistent with the fact that very few $\mathrm{CD}^{+}$cells were present at this stage in the intestine (Figure 3d, e). Further analysis showed that most of these cytokines (IL-22, IL-17, IFN- $\gamma$, and GM-CSF) were produced by Lin $^{-}$Thy $^{+}{ }^{+}$Sca- $1^{\text {hi }}$ ILCs (Figure $4 c)$. The vast majority (80-95\%) of Thy ${ }^{+}$Sca- ${ }^{\text {hi }}$ ILCs produced IL-22 (Supplementary Figure S5a). Approximately $30 \%$ of the Thy ${ }^{+}$Sca- $1^{\text {hi }}$ ILCs produced only IL-22 and the remaining cells co-expressed it with IL-17, IFN- $\gamma$, or GM-CSF (Supplementary Figure S5a). Of note, we observed that $\sim 6 \%$ of the cytokine-expressing cells, expressed IL-22, IL-17, IFN- $\gamma$, and GM-CSF (Supplementary Figure S5b). Together these results indicate that the distinct Thy $1^{+} \mathrm{Sca}-1{ }^{\mathrm{hi}}$ ILC population present in the neonatal intestine of V23 transgenic mice most closely resembles the NCR-negative ILC3s reported in adult host. ${ }^{4,5}$

\section{ILC3s and neutrophils co-localize in cellular aggregates} beneath the intestinal erosive lesions

Having detected the presence of Thy $1^{+}$Sca- $1{ }^{\text {hi }}$ ILC3s in the SI of V23 mice, we investigated next their distribution. To do so, 

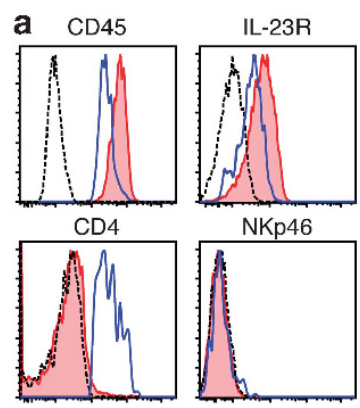

NKp46

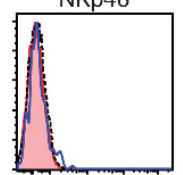

b

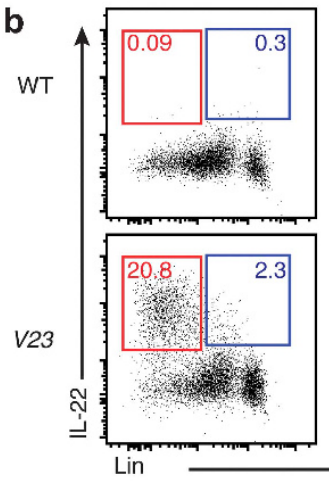

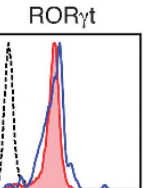

CCR6
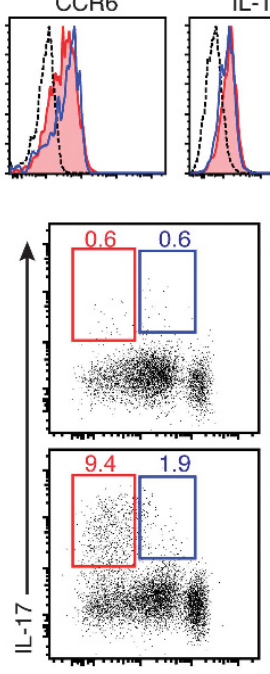

CD127

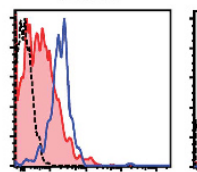

IL-18R
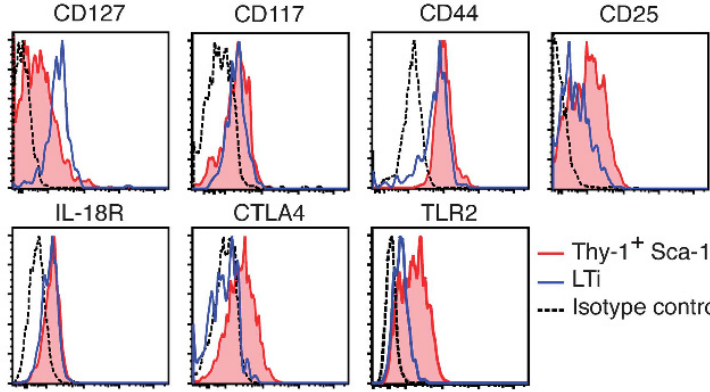

TLR2
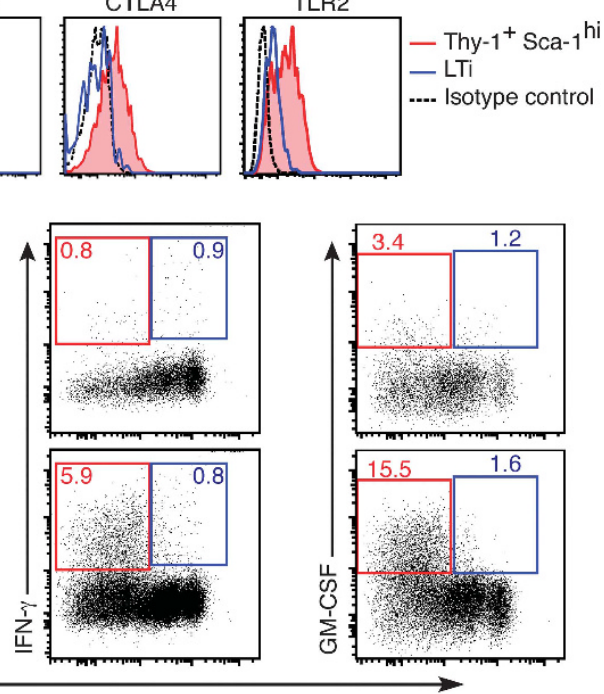

C
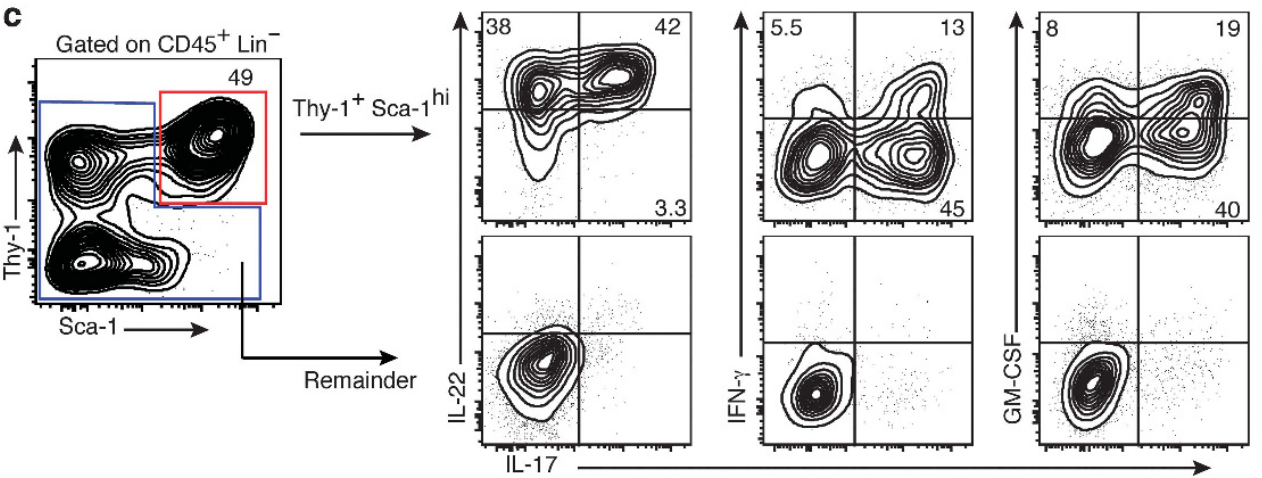

Figure 4 Thy $1^{+}$Sca- $1^{\text {hi }}$ cells in the intestine of the V23 mice are NCR ${ }^{-}$ILC3s. (a) Phenotype of lineage-negative $\left(\right.$Lin $^{-}, \mathrm{CD}^{-} \mathrm{B}^{-} 20^{-} \mathrm{CD}^{-11 b^{-}}$ Gr-1 $1^{-}$Ter $119^{-}$) Thy $1^{+}$Sca- $1^{\text {hi }}$ cells. Histograms are electronically gated on Lin ${ }^{-}$cells. Red lines indicate Lin ${ }^{-}$Thy $1^{+}$Sca- $1^{\text {hi }}$ ILC3, blue lines denote lymphoid tissue inducer ( $\mathrm{LTi})$ cells ( $\mathrm{Lin}^{-} \mathrm{CD}^{+}$), and dotted black lines indicate isotype controls. (b) Expression of indicated cytokines analyzed by flow cytometry on the $\mathrm{CD}_{4} 5^{+} \mathrm{Lin}^{+}$and $\mathrm{CD} 45^{+} \mathrm{Lin}^{-}$populations after stimulation with phorbol 12-myristate 13-acetate (PMA) and ionomycin. Dot plots show cells gated on $\mathrm{CD}_{4} 5^{+}$. Outlines areas in red indicate $\mathrm{Lin}^{-}$and outlines areas in blue indicate $\mathrm{Lin}^{+}$. (c) Intracellular cytokine expression by Lin ${ }^{-}$Thy $1^{+}$Sca- $1^{\text {hi }}$ cells (red) in comparison with remaining cells (blue) from the small intestine of $V 23$ mice at postnatal day 0 (P0) following stimulation with PMA and ionomycin. Data are representative of at least three independent experiments.

we first performed anti-Thyl immunostaining. We found Thy $1^{+}$cells in the erosive lesions, but not in adjacent areas (Figure 5a). These cells were interspersed among cells expressing the intercellular adhesion molecule (ICAM)-1, which is commonly expressed within lymph nodes and Peyer's patches (PPs) anlagen (Figure 5a). To further confirm the presence of cytokine-producing cells in these areas, we performed laser capture microdissection of the erosive lesions and the adjacent areas of the intestine of V23 mice, extracted mRNA and performed quantitative reverse transcriptase-PCR analysis for cytokines (Figure 5b). As control, we investigated cytokine mRNA expression in samples collected from PP's anlagen and adjacent areas of WT mice (Figure 5b).
Quantitative reverse transcriptase-PCR results showed that with the exception of IL-17, no cytokines were expressed in PPs of WT mice at this point (Figure 5c). In contrast, IL-22, IL-17, IFN- $\gamma$, and GM-CSF mRNA were all expressed in the areas corresponding to the erosive lesions of V23 mice compared with all other microdissected samples (Figure 5c), suggesting that cytokine-producing ILC3s clustered in the erosive lesions. IL-22 immunofluorescence staining subsequently confirmed that cells expressing IL-22 localized to cell clusters under the erosive lesions in the SI of V23 mice (Figure 5d).

Besides expressing cytokines, ILC3s express chemokine receptors such as CXCR5 (Supplementary Figure S6) and CCR6 (Figure 4a). We tested next if the presence of ILC3s in the 

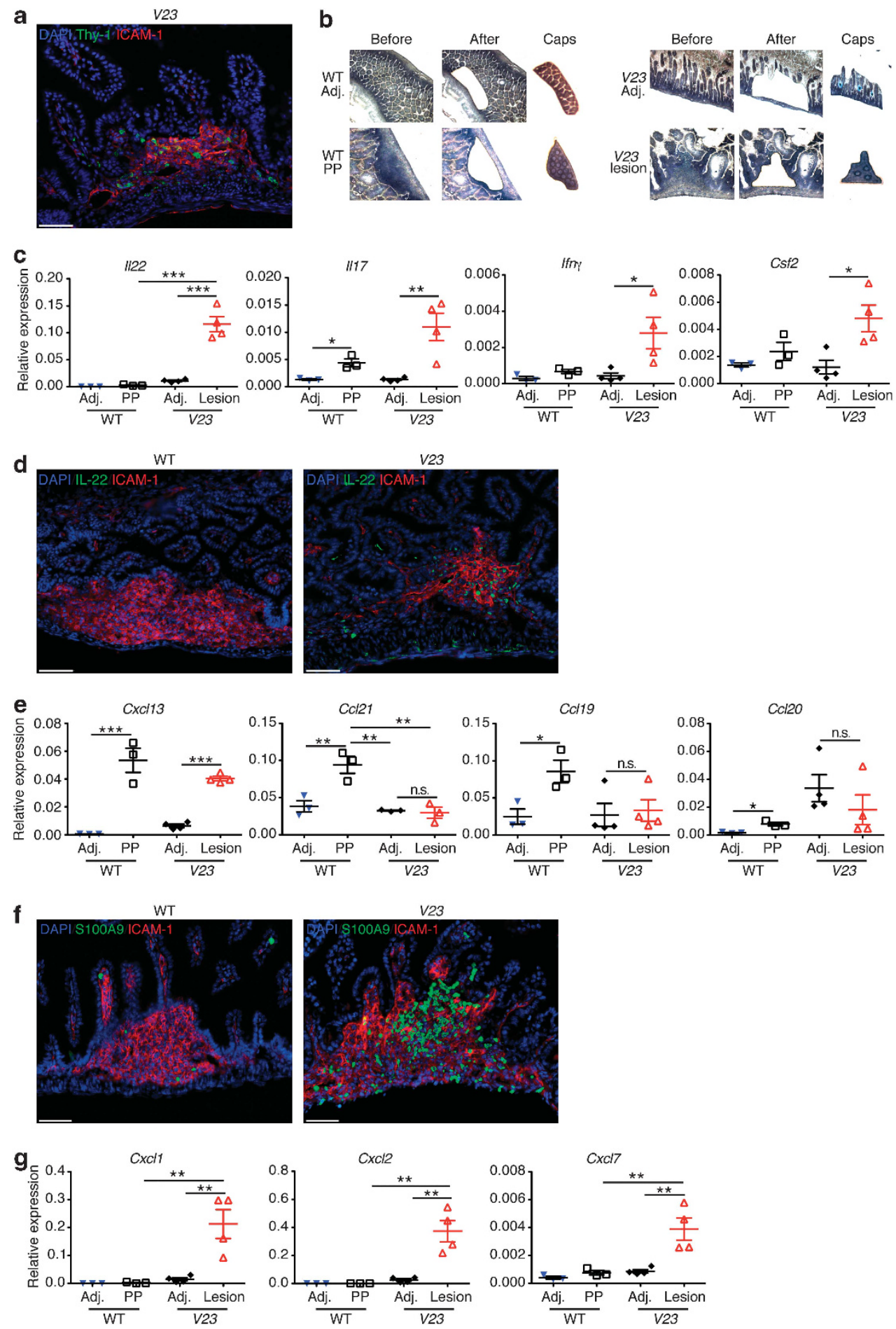

Figure 5 Thy $1^{+}$Sca-1 ${ }^{\text {hi }}$ ILC3s are located within erosive lesions in the intestine. (a) Immunofluorescence staining of the small intestine at postnatal day 0 (P0) showing the presence of thymocyte differentiation antigen $1\left(\right.$ Thy $^{+}{ }^{+}$) cells in intercellular adhesion molecule-positive $\left(\right.$ICAM ${ }^{+}$) cells aggregates in V23 mice (Thy1, green; ICAM-1, red; cell nuclei, 4',6-diamidino-2-phenylindole (DAPI)). Bar $=50 \mu \mathrm{m}$. (b) Histology of snap-frozen small intestine from wild-type (WT) and V23 mice. Slides show tissue before (left), after (middle) laser microdissection, as well as excised tissue in caps (right). (c) Cytokine expression measured by quantitative reverse transcriptase-PCR (RT-PCR) in microdissected Peyer's patches anlagen (PPs)/erosive lesions areas (lesion) and adjacent control areas (Adj) isolated from P0 WT and V23 mice. Means \pm s.e.m., $n=4$ per group. ${ }^{*} P<0.05,{ }^{* *} P<0.01,{ }^{* * *} P<0.001$. (d) Immunofluorescence staining of the small intestine of V23 mice at P0 showing the presence of interleukin-22 (IL-22) ${ }^{+}$cells within ICAM $^{+}$aggregates (IL-22, green; ICAM-1, red; cell nuclei, DAPI). Bar $=50 \mu \mathrm{m}$. (e) Chemokine expression in microdissected PPs anlagen/erosive lesions areas (lesion) and adjacent control areas (Adj) isolated from P0 WT and V23 mice. Means \pm s.e.m., $n=4$ per group. NS, not significant, ${ }^{*} P<0.05,{ }^{* *} P<0.01,{ }^{* * *} P<0.001$. (f) Immunofluorescence staining of the small intestine at P0 showing the presence of neutrophils $\left(\mathrm{S} 100 \mathrm{Ag}^{+}\right)$in ICAM ${ }^{+}$cells aggregates (S100A9, green; ICAM-1, red; cell nuclei, DAPI). Bar $=50 \mu \mathrm{m}$. (g) Expression of neutrophil chemoattracting chemokines in microdissected PPs anlagen/erosive lesions areas (lesion) and adjacent control areas (Adj) isolated from P0 WT and V23 mice. Means \pm s.e.m., $n=4$ per group, ${ }^{\star \star} P<0.01$. 
erosive lesions was associated with increased expression of CXCL13 and CCL20, ligands for CXCR5 and CCR6, respectively. In the WT intestine CXCL13, along with CCL19 and CCL21, is expressed constitutively in PPs. ${ }^{38-40}$ Consistent with these previous findings, we detected increased expression of Ccl19, Ccl21, and Cxcl13 within ICAM-1 ${ }^{+}$PPs anlagen of P0 WT mice (Figure 5e). In V23 mice, expression of ICAM-1 localized to the erosive lesions, and increased levels of Cxcl13 mRNA were detected compared with neighboring areas (Figure 5e). Ccl19 and Ccl21 mRNA levels did not differ between erosive and adjacent areas (Figure 5e). Ccl20 mRNA was only modestly increased in PPs of controls and did not differ between erosive and adjacent areas of V23 intestine (Figure 5e). These results suggest that CXCL13 may be important for recruitment of ILC3s into the ICAM- ${ }^{+}$erosive areas of the V23 intestine.

Because neutrophil numbers were also increased in the SI of V23 mice (Figure 3f), we examined next their distribution. Neutrophils were abundant in the same areas where ILC3s were found (Figure 5f). Ultrastructural analysis showed that neutrophils migrated from the lamina propria to the lumen and disrupted the epithelium (Supplementary Figure S7), leading to formation of the erosive lesions. Of note, we found that cells isolated from the erosive lesions in V23 mice expressed higher levels of neutrophil-recruiting chemokines $\mathrm{Cxcl1}, \mathrm{Cxcl} 2$, and $\mathrm{Cxcl} 7$ than those from adjacent control areas or from PPs anlagen of WT mice (Figure 5g).

Together the data indicate that ILC3s and neutrophils colocalize in cellular aggregates beneath the intestinal erosive lesions, and suggest that specific chemokines may be involved in their recruitment to those sites.

\section{Thy $1^{+}$Sca- $1^{\text {hi }}$ ILCs contribute to neonatal intestinal pathology}

IL-23-responsive $\mathrm{NCR}^{-}$ILC3s mediate intestinal immune pathology in adult murine models of colitis. ${ }^{4,6}$ To test if the Thy ${ }^{+}$Sca- $1^{\text {hi }}$ ILC3s could contribute to the neonatal pathology observed in the V23 mice, we first injected an anti-Thy1 monoclonal antibody into pregnant mice and newborn pups, and estimated the frequency of Thy ${ }^{+}$Sca- $1^{\text {hi }}$ ILCs in their offspring at P4 (Figure 6a). Anti-Thy1 monoclonal antibody injection reduced the total number of $\mathrm{Thy}^{+}{ }^{+} \mathrm{Sca}-1^{\text {hi }}$ cells in V23 mice (Figure 6b). These animals had fewer erosive lesions in the intestine (Supplementary Figure S8a) and survived longer than the V23 mice treated with isotype control antibodies (Figure 6c).

To genetically deplete the ILC3 population, we intercrossed the V19 and V40 mice to mice deficient in the Rorc to generate V23Rorc ${ }^{-1-}$ mice. ROR $\gamma \mathrm{t}$-deficient mice lack all ILC3s. ${ }^{12}$ At birth, V23 Rorc $^{+/-}$mice had fewer Thy ${ }^{+}$Sca- ${ }^{\text {hi }}$ ILC3s than V23 mice (Figure 6d) and survived longer than V23 mice (Figure 6e). As expected, V23 Rorc ${ }^{-1-}$ mice did not have Thy $1^{+}$Sca- $1^{\text {hi }}$ ILCs (Figure 6d) and survived to adulthood (Figure 6e). Accordingly, there were no erosive lesions present in the intestine of V23 Rorc ${ }^{-1-}$ mice (Supplementary Figure S8b) consistent with the fact that ROR $\gamma \mathrm{t}$-deficient mice lack PPs. ${ }^{41}$ Similar to V23 Rorc ${ }^{-1-}$ mice, no Thy ${ }^{+}$Sca- ${ }^{\text {hi }}$ ILCs were present in $\mathrm{V} 23 \mathrm{Il}-23 \mathrm{r}^{\mathrm{gfp} / \mathrm{gfp}}$ mice (Supplementary Figure S9) that survived to adulthood (Figure 2f).

At birth, few T cells are present in the intestine (Figure 3d, e). To rule out a contribution of $\mathrm{T}$ cells to the phenotype observed in V23 mice, we intercrossed the V19 and V40 mice to RAG1 ${ }^{-1-}$ mice and to mice deficient in the gamma delta $\mathrm{T}$-cell receptor $\left(\mathrm{Tcrd}^{-1-}\right)$ to generate $\mathrm{V} 23 \mathrm{RAG1^{-1- }}$ and $\mathrm{V} 23 \mathrm{Tcrd}^{-1-}$ mice,
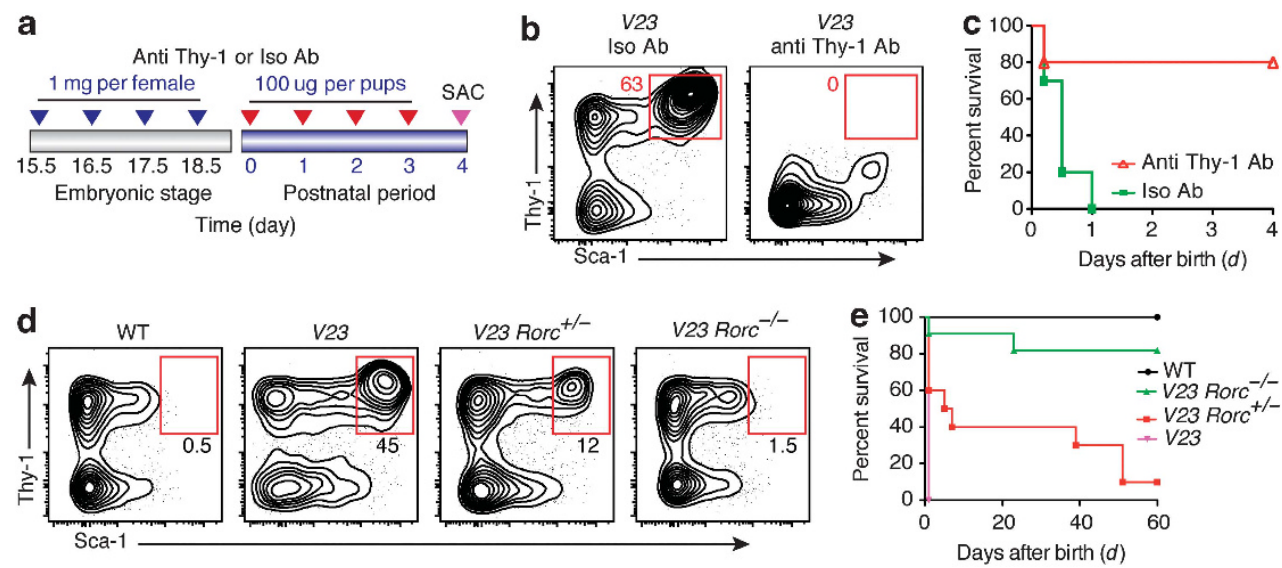

Figure 6 Thy $1^{+}$Sca- $1^{\text {hi }}$ ILC3s are the main drivers of the intestinal pathogenesis. (a) Protocol used for in vivo depletion of thymocyte differentiation antigen $1\left(\mathrm{Thy}_{1}{ }^{+}\right.$) cells in newborn V23 mice. The pregnant mothers were administered intravenously with 1 mg rat anti-Thy 1 monoclonal antibody (mAb) or $1 \mathrm{mg}$ isotype control $\mathrm{mAb}$ at gestational days $15.5,16.5,17.5$, and 18.5 . After birth, pups were injected intraperitoneally (i.p.) daily with $100 \mu \mathrm{g}$ anti-Thy 1 $\mathrm{mAb}$ or $100 \mu \mathrm{g}$ isotype control per mouse for 4 days. (b) Flow cytometric analysis of the Lin ${ }^{-}$Thy $1^{+}$Sca- $1^{\mathrm{hi}}$ population in the small intestine after antibody injection. Dot plots show cells gated on CD45 ${ }^{+} \mathrm{Lin}^{-}$. (c) Survival curves of V23 pups treated with anti-Thy1 $(n=12)$ or isotype $(n=12)$. ${ }^{*} P<0.01$ between groups by Log-rank test. (d) Flow cytometry plot showing the proportion of Lin ${ }^{-}$Thy $1^{+} \mathrm{Sca}-1^{\mathrm{hi}}$ cells in the small intestine of V23, V23Rorc $(\gamma \mathrm{t}){ }^{+/}-{ }^{-}$, and V23Rorc $(\gamma \mathrm{t})^{-1-}$ mice at postnatal day 0 (P0). Dot plots show cells gated on CD45 ${ }^{+} \mathrm{Lin}^{-}$. (e) Survival curves of V23 $(n=15), V 23 R o r c(\gamma \mathrm{t}){ }^{+\prime-}(n=18)$, and V23Rorc $(\gamma \mathrm{t})^{-1-}(n=22)$ mice. ${ }^{* * *} P<0.001$ between V23Rorc $(\gamma \mathrm{t})^{+/-} /$V23Rorc $(\gamma \mathrm{t})^{-1-}$ mice and V23mice by Log-rank test. Data are representative of three independent experiments. 

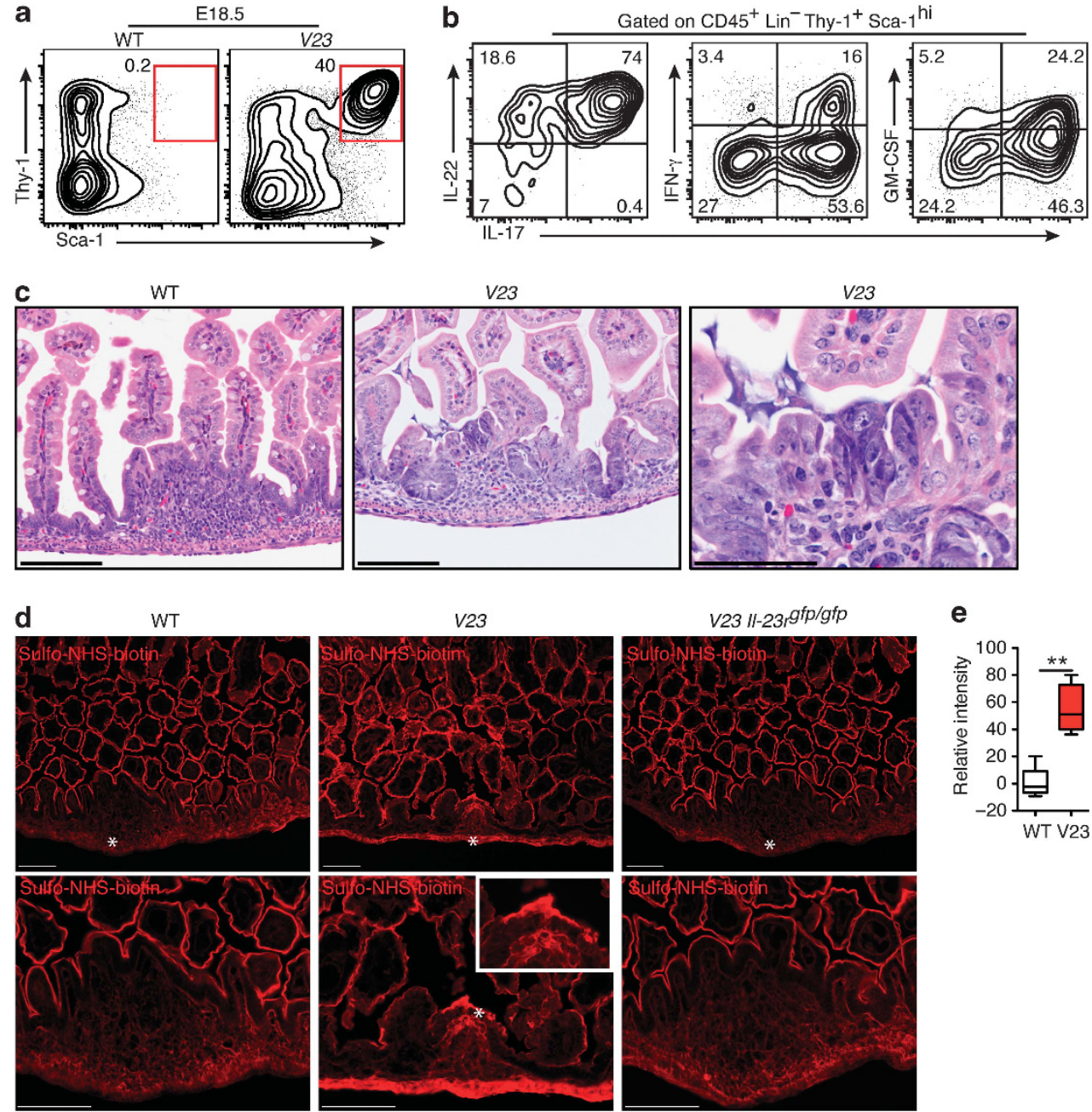

Figure 7 Intestinal Thy $1^{+}$Sca- $1^{\text {hi }}$ ILCs dysregulate epithelial permeability at prenatal stage. (a) Flow cytometric analysis of the Lin ${ }^{-}$Thy $1^{+}$Sca- $1^{\text {hi }}$ cells in the small intestine of mice at embryonic day E18.5. Dot plots show cells gated on CD45 ${ }^{+}$Lin $^{-}$. (b) Representative cytokine expression profile of Lin ${ }^{-}$Thy $1^{+}$Sca-1 ${ }^{\text {hi }}$ ILC3s present in the small intestine of embryonic V23 mice (E18.5). (c) Representative hematoxylin and eosin (H\&E)-stained sections of the small intestine of wild-type (WT) and V23embryo mice (E18.5). Bar $=100 \mu \mathrm{m}$. (d) The fluorescence staining of proteins labeled with sulfoNHS-biotin in the small intestine after injection of the probe into the lumen of the intestine of embryos at E18.5. Stars indicate cellular aggregates in the gut. $\mathrm{Bar}=100 \mu \mathrm{m}$. Zoomed-in boxed area shows fluorescence staining of cellular aggregates in V23 mice. Data are representative of three independent experiments. (e) Quantification of relative fluorescent intensity in the Peyer's patches (PPs) anlagen of WT mice (2-5 sections for each mouse) and in erosive lesions of V23 mice (4-10 sections for each mouse). Data are shown as means \pm s.e.m. of $n=5$ mice per group. ${ }^{\star \star} P<0.01$.

respectively. V23 $R A G 1^{-1-}$ and $V 23 \quad \mathrm{Tcrd}^{-1-}$ mice succumbed immediately after birth and presented erosive lesions (Supplementary Figure S10) similar to those noted in V23 mice (Figure 2d and Supplementary Figure S10). Together, these results indicate that Thy ${ }^{+} \mathrm{Sca}-1^{\mathrm{hi}}$ ILC3s, but not $\mathrm{T}$ and $\mathrm{B}$ cells, have a critical role in neonatal intestinal pathology and perinatal death of V23 mice.

\section{Intestinal embryonic Thy $1{ }^{+}$Sca- ${ }^{\text {hi }}$ ILC3s dysregulate epithelial permeability}

We examined next whether the $\mathrm{NCR}^{-}$ILC3s were present during the prenatal stage. We found that Thy $1^{+} \mathrm{Sca}-\mathrm{h}^{\mathrm{hi}}$ ILC3s were present in the V23, but not WT fetuses, prior to birth (Figure 7a) and that the relative number of these cells was not different between late fetal stages and birth (Figure 3a and 7a).
As some studies indicate that commensal-derived signals may also contribute to ILCs function, ${ }^{22,42}$ we analyzed next the cytokine production by Thy $1^{+}$Sca- $1^{\text {hi }}$ ILC3s in prenatal period. We found that fetal Thy ${ }^{+}{ }^{+}$Sca- $1{ }^{\text {hi }}$ ILC3s (Figure $7 \mathbf{b}$ ) expressed IL-22, IL-17, IFN- $\gamma$, and GM-CSF similar to the postnatal Thy $1^{+}$Sca- $1^{\text {hi }}$ ILC3s (Figure 4c).

Given that cytokine-producing Thy ${ }^{+}{ }^{\text {Sca- }}{ }^{\text {hi }}$ ILC3s could be found in the embryonic gut, we asked next if they could promote prenatal pathology. Histopathological analysis of the intestine of V23 fetuses at E18.5 showed no epithelial disruption or intestinal bleeding, but revealed the presence of cellular aggregates with few scattered subepithelial neutrophils (Figure 7c). Quantitative reverse transcriptase-PCR analysis of sorted epithelial cells of $V 23$ mice revealed that epcam, cldn 1 , $2,3,7$, and $c d h 1$ expression was downregulated in V23 mice 
compared with controls (Supplementary Figure S11). These results suggested a possible dysfunction in epithelial permeability. To test this hypothesis, we injected the intestinal lumen of E18.5 V23 and WT embryos with sulfo-NHS-biotin, a probe that labels cell membrane proteins. ${ }^{43}$ As control, we examined the biotin signal at the intestinal epithelium of WT mice. The intestine of the WT mouse was uniformly labeled, with no dye being detected in the lamina propria (Figure 7d). The intensity of the biotin signal in areas of the lamina propria, especially in the area corresponding to the cellular aggregates, was higher in the V23 mice than in WT mice (Figure 7d, e), suggesting increased permeability of the epithelium at those sites. We also examined, as an additional control, the intestine of $\mathrm{V} 23 \mathrm{Il}$ $23 r^{g f p / g f p}$ mice injected with sulfo-NHS-biotin. The results were similar to those obtained with WT mice (Figure 7d), which ruled out the possibility that the dysregulated intestinal epithelial permeability in the $V 23$ mice resulted from a transgenic artifact.

Together the findings indicate that V23 mice had downregulation in the expression of genes involved in maintaining the epithelial barrier, and increased permeability of the epithelium in areas rich in cytokine-producing $\mathrm{NCR}^{-} \mathrm{Thyl}^{+}$ Sca- ${ }^{\text {hi }}$ ILC3s.

\section{Commensal bacteria aggravate intestinal pathology induced by Thy $1^{+}$Sca- $1^{\text {hi }}$ ILCs after birth}

As demonstrated above, cytokine-producing ILC3s were present in the embryonic V23 intestine and their presence was associated with increased epithelial permeability. Yet, no significant damage or mortality was observed in embryos, suggesting that ILC3s were necessary, but not sufficient to induce the full phenotype. We next tested the hypothesis that the microbiota could contribute to the neonatal phenotype. Bacterial colonization of the newborn intestinal tract starts as the fetuses pass the birth canal and continues with the initial feeding and exposure to the environment. We thus tested if there were differences in the initial colonization of the intestine between WT and V23 mice. We subjected DNA collected from the SI of P0 V23 and WT littermate controls to 16S rDNA sequencing. Weighted UniFrac distances (PC1, $P=0.82$; Supplementary Figure S12a) and alpha diversity analysis $(P>0.9$, Supplementary Figure $\mathbf{S 1 2 b})$ indicated that the microbiota of V23 mice was similar to that of WT littermate controls. Analysis of the most abundant phyla did not indicate any major changes in the relative abundance between V23 and WT littermate controls (Supplementary Figure S12c). In total, 156 individual operational taxonomic units were retained after quality filtering, none of which showed a significant difference between V23 and WT mice $(q>0.05$, Supplementary Figure S12d).

Having demonstrated that the expression of IL-23 and increased numbers of ILC3s did not affect the initial bacterial colonization of the gut, we tested next if a reduction of the bacterial load would affect the phenotype. To reduce the exposure of newborn V23 mice to bacteria, we treated pregnant mothers with antibiotics. Antibiotic treatment prolonged the survival and decreased the number of intestinal erosive lesions in the newborn V23 mice (Figure 8a, b), implicating the role of the microbiota in ILC3s-induced pathogenesis. Of note, we found a reduced neutrophil infiltrate in the intestine of antibiotic-treated V23 mice (Figure 8c), suggesting that neutrophil accumulation in the ulcers could be due in part to the intestinal bacterial colonization.

We next examined if bacteria affected the phenotype by affecting the number or activity of ILC3s. There were no significant differences in the number of Thy ${ }^{+}$Sca- ${ }^{\text {hi }}$ ILC3s between antibiotic-treated and -untreated V23 mice (Figure 8d, e). We then examined gene expression in highly purified intestinal $\mathrm{Thy}^{+}{ }^{+} \mathrm{Sca}-\mathrm{h}^{\mathrm{hi}}$ ILC3s from non-treated, and antibiotic-treated neonatal V23 mice. No significant differences were observed in the expression of surface markers (Il23r, Kit, Cd44, Cxcr5, Ccr6, Il18r1, Ctla4, and so on) or cytokines (Il22, Il17a, Ifng, and Csf2) (Supplementary Figure S13) between these two groups. The expression of ILC3s signature cytokine genes was also similar between non-antibiotic-treated fetal and postnatal Thy $1^{+}$Sca- ${ }^{\text {hi }}$ ILC3s (Supplementary Figure S13), cor-roborating the results reported above (Figure $4 \mathrm{c}$ and $7 \mathrm{a}, \mathrm{b}$ ).

These results indicated that Thy $1^{+} \mathrm{Sca}-1^{\text {hi }}$ ILC3s were necessary but not sufficient for the neonatal intestinal pathology observed in V23 mice. Bacterial colonization at birth exacerbates pathology induced by these cells and promotes neonatal death.

\section{DISCUSSION}

Most studies to date have examined IL-23 biology during the course of bacterial infections and/or gastrointestinal tract injury in the adult host, but a direct role for IL-23 in the activation and function of neonatal ILC3s has not yet been investigated. Results shown in the present study indicate that dysregulated expression of IL-23 during the immediate neonatal period promotes development of a population of ILCs with pathogenic properties.

At birth, the mouse intestine is populated by few $\mathrm{T}$ cells (Figure 3d, e), but is home to myeloid cells and ILCs that express the IL-23R. ${ }^{2,12,13}$ Here, we have used in vitro approaches (Figure 1) and reductionist genetic models (Figure 2) to examine the contribution of IL-23 to the activation and function of these IL-23R ${ }^{+}$ILC3s. Using an in vitro culture system, we demonstrated that IL-23 directly promoted development of IL-22-producing Thy $1^{+} \mathrm{Sca}^{-1}{ }^{\mathrm{hi}}$ ILC3s. We also show that gut-specific expression of IL-23 expanded this population in the neonatal intestine. Together these results indicate that expression of IL-23 promotes development and function of Thy $1^{+}$Sca- ${ }^{\text {hi }}$ ILC3s in the neonatal intestine. These neonatal $\mathrm{Thyl}^{+}{ }^{+} \mathrm{Sca}-1^{\text {hi }}$ ILC3s (Figure 4) shared similarities with a $\mathrm{NCR}^{-}$ILC3 population found in the adult colon by other groups. ${ }^{4,6}$ Neonatal Thy $1^{+}$Sca- $1{ }^{\text {hi }} \mathrm{NCR}^{-}$ ILC3s concentrated in the SI and were found in clusters with $\mathrm{ICAM}^{+}$cells and neutrophils in areas that resembled PPs anlagen (Figure 5). Thy ${ }^{+}$Sca- $1^{\text {hi }} \mathrm{NCR}^{-}$ILC3s expressed LTi-related genes such as LT- $\alpha$, LT- $\beta$, and TRANCE, ${ }^{4}$ but were 

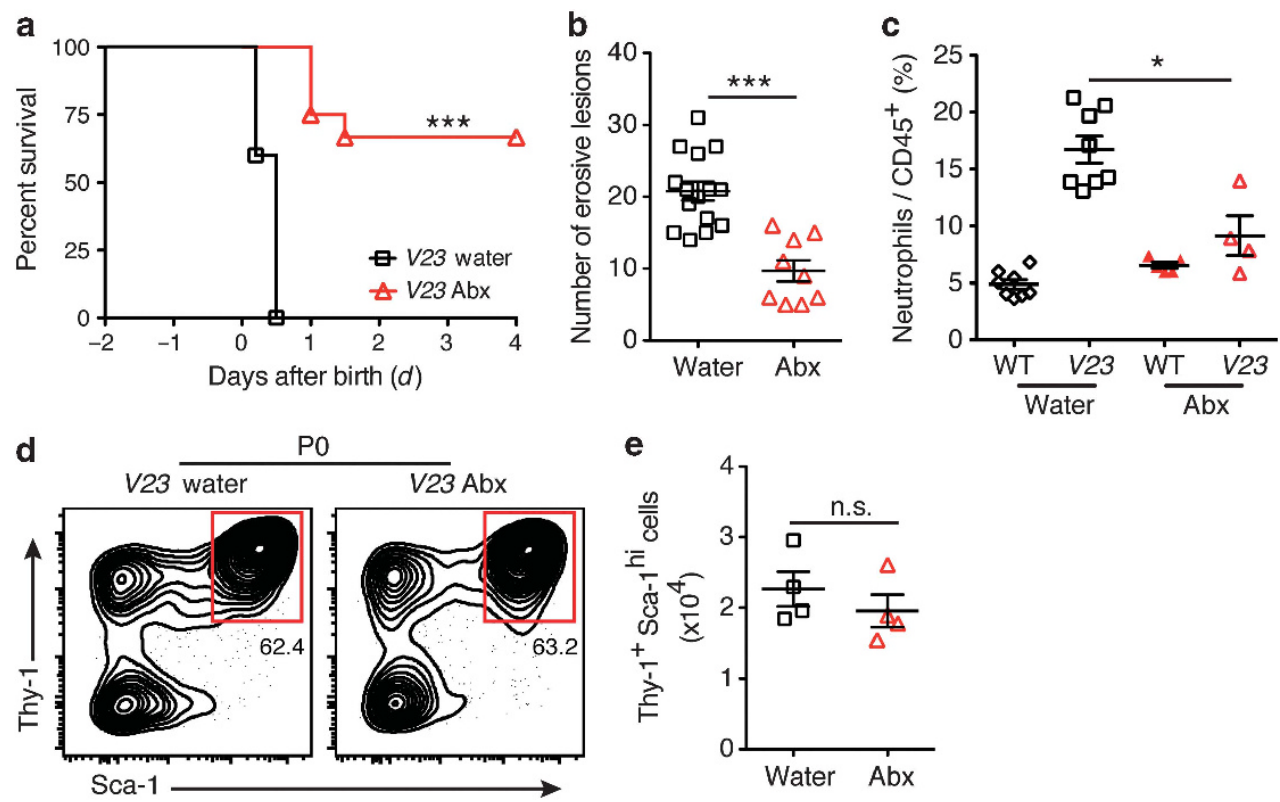

Figure 8 Commensal bacteria aggravate intestinal pathology induced by Thy $1^{+}$Sca- $1^{\text {hi }}$ ILCs. (a) Survival curves of V23 mice derived from mothers treated with $(n=22)$ or without $(n=15)$ an antibiotic cocktail in drinking water during pregnancy. ${ }^{* \star *} P<0.001$ between groups by Log-rank test. (b) Number of erosive lesions in the intestine of $V 23$ mice born from mothers receiving water or antibiotic. Data are shown as means \pm s.e.m., $n=9-14$ for each group, ${ }^{\star * \star} P<0.001$. (c) Relative number of neutrophils $\left(C D 11 b^{+} \mathrm{Gr}-1^{+}\right)$in the small intestine of $V 23$ mice born from mothers receiving water or antibiotic. Data are shown as means \pm s.e.m., $n=4-8$ per group, ${ }^{*} P<0.05$. (d, e) Relative (d) and absolute (e) number of the Lin ${ }^{-}$Thy $1^{+}$Sca- $1^{\text {hi }}$ cells in the small intestine of $V 23$ mice born from mothers receiving water or antibiotic. Data are shown as means \pm s.e.m., $n=4$ for each group. Dot plots show cells gated on $\mathrm{CD} 45^{+} \mathrm{Lin}^{-}$. NS, not significant.

not canonical LTis, because they did not express CD4 (Figure 4a). However, similar to $\mathrm{LTi}$, Thy $1^{+} \mathrm{Sca}_{-1}{ }^{\mathrm{hi}} \mathrm{NCR}^{-}$ILC3s expressed IL23R and the chemokine receptor CXCR5, which is responsive to CXCL13, a chemokine expressed in lymphoid anlagen. The fact that these two cell populations express many similar markers and are located in the same intestinal area suggests that they may share a common developmental origin. It remains to be tested if IL-23 stimulates further differentiation of LTi into pathogenic Thy $1^{+} \mathrm{Sca}-\mathrm{h}^{\mathrm{hi}} \mathrm{NCR}^{-}$ILC3s or whether it acts on a common precursor that is recruited into the anlagen.

There appears to be significant heterogeneity within ILC3s in the adult intestine. Some ILC3s are predominantly IL-22 producers, some primarily produce IL- 17 , while others can produce IFN- $\gamma^{4,6,44}$ It is unclear if these represent different subsets of cells, or if this reflects different cytokine expression profiles in response to environmental signals. In a murine model of Helicobacter hepaticus-mediated colitis, ROR $\gamma \mathrm{t}^{+}$ ILCs in the colon produce IL-17A and IFN- $\gamma$ and depletion of these cells prevents colitis. ${ }^{4}$ ILC3s secreting IL-17A, but little IFN- $\gamma$, have also been implicated in the pathogenesis

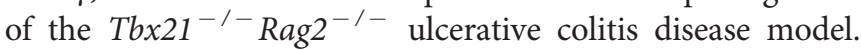
Treatment with a Thy1-specific antibody also ameliorates disease in this setting. ${ }^{6}$ Here we show that IL-23-induced Thy ${ }^{+}$Sca- ${ }^{\text {hi }}$ ILCs express only IL-22 in vitro (Figure 1g). In vivo, the Thy $1^{+}$Sca- $1{ }^{\text {hi }}$ ILCs induced by IL-23 produce several cytokines, including IL-17, IL-22, IFN- $\gamma$, and GM-CSF (Figure 4c). Most cells produced IL-22 and IL-17, but cells expressing different combinations of cytokines, or even all cytokines simultaneously, were also identified. To our knowledge, the existence of a population expressing all these cytokines simultaneously has not been previously demonstrated.

Our results indicate that increased IL-23 signaling in the immature, early intestine, led to an exaggerated generation of $\mathrm{NCR}^{-}$ILC3s, and to uncontrolled production of cytokines. These ILC3s are likely to be the main drivers of the pathogenesis because they were the main cytokine producers. The few $\mathrm{T}$ cells present at this stage did not produce cytokines, nor do the $\gamma \delta \mathrm{T}$ cells or other $\mathrm{Lin}^{+} / \mathrm{Lin}^{-}$populations. Furthermore, reduction or ablation of $\mathrm{NCR}^{-}$ILC3, but not T and B cells (Supplementary Figure S10), reduced or eliminated disease, suggesting that this population is critical for pathogenesis in the neonatal gut.

Group 3 ILCs include LTi cells, $\mathrm{NCR}^{+}$ILC3s and NCR $^{-}$ ILC3s. ${ }^{13}$ LTi cells develop in the microbiota-free environment of the fetus before birth, ${ }^{14,15}$ whereas NKp46 ${ }^{+}$ROR $\gamma \mathrm{t}^{+}$ILC3s only appear after birth and are not found in embryonic mice. ${ }^{21,23}$ Thy ${ }^{+}$Sca- ${ }^{\text {hi }}$ ILC3s were present in the V23 fetal intestine (Figure 7a), but did not appear to cause pathology, suggesting that they were necessary, but not sufficient to cause disease. Results shown here indicate that antibiotic treatment of pregnant mothers prolonged survival of V23 offspring (Figure 8a), suggesting that commensal bacterial-derived signals affected the pathology induced by $\mathrm{Thyl}^{+} \mathrm{Sca}-1^{\text {hi }}$ ILC3s. Despite being localized near barrier surfaces populated by commensal flora, ${ }^{45}$ ILC3s did not affect the initial 
bacterial colonization of the intestine (Supplementary Figure S12). Bacterial colonization did not affect the numbers of ILC3s or the expression of signature cytokines by these cells (Figure 8e and Supplementary Figure S13). Our results suggest that ILC3s induced pathology by altering barrier integrity (Figure 7d and Supplementary Figure S11). Penetration of bacteria or bacterial products through areas of ILC3-induced increased permeability located in the anlagen, could lead to uncontrolled bacterial proliferation, cytokine storm, and death.

Our findings may have relevance for understanding the development of intestinal inflammatory diseases of the neonate. The fetus and young infant have a high susceptibility to infections with pathogens, suggesting that immune responses are different in early life. ${ }^{46}$ It is generally accepted that this increased susceptibility is related to the immaturity/ deficiencies of the neonatal immune system. However, there is evidence that some responses rather than inhibited, are exaggerated. For instance, human neonatal DCs, respond to Toll-like receptor stimulation by secreting large amounts of IL$23 .^{27-29}$ Robust expression of IL-23 by DC after bacterial exposure could trigger development and activation of ILC3 in the neonatal gut and lead to disease. In this context, it is important to note that IL-23 expression has been detected in the neonatal ileum of experimental models of necrotizing enterocolitis. ${ }^{47}$ Necrotizing enterocolitis is the most common inflammatory disease of the gastrointestinal tract of preterm infants. ${ }^{48}$ The etiology of necrotizing enterocolitis is obscure, but the disease is characterized by intestinal bleeding, mucosal intestinal necrosis, and bacterial translocation. Increased bacterial translocation could trigger IL-23 production and expansion of pathogenic $\mathrm{NCR}^{-}$ILC3s. It will be thus important to investigate if IL-23 and IL-23-responsive-ILC3s play a role in necrotizing enterocolitis pathogenesis.

In conclusion, the data presented in this study demonstrate that increased levels of IL-23 in the neonatal intestine can trigger development of $\mathrm{Lin}^{-} \mathrm{ROR} \gamma \mathrm{t}^{+} \mathrm{Thy}^{+}{ }^{+} \mathrm{Sca}-1^{\text {hi }}$ ILC3s that act in concert with commensal bacteria to promote severe pathology. Thus, our results reveal a novel role for the IL-23-ILC3s axis in the pathogenesis of neonatal intestinal inflammation.

\section{METHODS}

Mice. The cDNA of IL-23p19 and IL-23p40 were cloned into a pBSVillin vector that contained a $9-\mathrm{kb}$ segment of the mouse villin promoter. ${ }^{35}$ Transgenic mice were produced in the C57BL/6J background using conventional methods. ${ }^{49}$ Identification of the transgenic V19 mice was done by PCR amplification using the following primers: 5'-GCCAGTTTCCCTTCTTCCTC-3' and $5^{\prime}$-GGCTAGCATGCAGAGATTCC- $3^{\prime}$. Identification of the transgenic $V 40$ mice was done by PCR amplification using the following primers: $5^{\prime}$-AATCCAGCGCAAGAAAGAAA- $3^{\prime}$ and 5'-CAAATGTGGT ATGGCTGATTATG-3'. V19 mice crossed to V40 mice to obtain V23 mice. C57BL/6, Rorc $(\gamma \mathrm{t})^{-1-}, \mathrm{Tcrd}^{-1-}$, and $R A G 1^{-1-}$ mice were purchased from The Jackson laboratory (Bar Harbor, ME). Il-23r $r^{-1-}$ mice were described before. ${ }^{34}$ Mice were maintained under specific pathogen-free conditions. All experiments involving animals were performed following guidelines of the Animal Care and Use Committee of the Icahn School of Medicine at Mount Sinai.
Flow cytometry and sorting. The SI, large intestine, and mesenteric lymph nodes of embryonic and P0 mice were microdissected using a stereo microscope and further digested with $2 \mathrm{mg} \mathrm{ml}^{-1}$ collagenase D (Roche, Indianapolis, IN). Cell suspension was passed through a $70-\mu \mathrm{m}$ cell strainer and mononuclear cells were isolated. Further details and list of antibodies used have been included in Supplementary Procedures.

The intracellular cytokine staining was measured after cells were stimulated for $6 \mathrm{~h}$ with phorbol 12 -myristate 13 -acetate $\left(50 \mathrm{ng} \mathrm{ml}^{-1}\right)$, and ionomycin $\left(1 \mu \mathrm{g} \mathrm{ml}^{-1}\right.$, both from Sigma-Aldrichm, St Louis, MO) in the presence of monensin $(2 \mu \mathrm{M})$ (eBioscience, San Diego, CA) for the final $4 \mathrm{~h}$ at $37^{\circ} \mathrm{C}$ culture (for details, see Supplementary Procedures).

Histology and immunofluorescence staining. Tissue was dissected, fixed in $10 \%$ phosphate-buffered formalin and then processed for paraffin sections. Five-micrometer sections were stained with hematoxylin and eosin. Immunofluorescence staining of frozen or paraffin-embedded tissues and list of antibodies are described in Supplementary Procedures.

Laser capture microdissection. Frozen tissue sections $(10 \mu \mathrm{m}$ in thickness) were cut under RNase-free conditions. Samples of intestine tissue were captured from the stained slides on Arcturus CapSure Macro LCM caps by using an ArcturusXT Microdissection microscope (Applied Biosystems, Carlsbad, CA) (for details, see Supplementary Procedures)

DNA extraction, 16S rDNA amplification, and multiplex sequencing. DNA was obtained from whole gut of P0 mice using the DNeasy Blood and Tissue Kit (QIAGEN, Valencia, CA). Bacterial 16S rRNA genes were amplified using the primers as described in Caporaso et al. ${ }^{50}$ Sample preparation and analysis of $16 \mathrm{~S}$ DNA sequence were done as previously described. ${ }^{51}$

Barrier function assay. The barrier function assay based on sulfo-NHSbiotin was performed as described previously ${ }^{43}$ (for details, see Supplementary Procedures). Mean fluorescence intensity in the PPs anlagen (WT mice) or erosive lesions (V23 mice) and corresponding adjacent tissues were analyzed on images set to a $5 \%$ pixel saturation using ImageJ v1.49a (NIH, Bethesda, MD). The data were expressed as relative fluorescence intensity representing subtraction of mean fluorescence intensity in adjacent tissue from PPs anlagen (WT mice) or erosive lesions (V23 mice).

Statistical analysis. Differences between groups were analyzed with nonparametric Mann-Whitney test. Survival curves were analyzed by a log-rank test. All statistical analyses were performed with GraphPad Prism 5 software (La Jolla, CA).

SUPPLEMENTARY MATERIAL is linked to the online version of the paper at http://www.nature.com/mi

\section{ACKNOWLEDGMENTS}

We thank Juan Lafaille, Daniel Mucida, and Andrea Cerutti for discussions. We thank Claudia Canasto-Chibuque for help with genotyping and Parinati Kharel for help with the antibiotic treatment of mice. We thank the Flow Cytometry, Mouse Genetics and Histology Shared Resource Facilities at Mount Sinai for technical advice and support. This study was supported by the NIH grant P01 DK072201 and by the SUCCESS grant to S.A.L.

\section{DISCLOSURE}

The authors declared no conflict of interest.

c 2015 Society for Mucosal Immunology

\section{REFERENCES}

1. Oppmann, B. et al. Novel p19 protein engages IL-12p40 to form a cytokine, IL-23, with biological activities similar as well as distinct from IL-12. Immunity 13, 715-725 (2000). 
2. Ahern, P.P., Izcue, A., Maloy, K.J. \& Powrie, F. The interleukin-23 axis in intestinal inflammation. Immunol. Rev. 226, 147-159 (2008).

3. Ahern, P.P. et al. Interleukin-23 drives intestinal inflammation through direct activity on T cells. Immunity 33, 279-288 (2010).

4. Buonocore, S. et al. Innate lymphoid cells drive interleukin-23-dependent innate intestinal pathology. Nature 464, 1371-1375 (2010).

5. Geremia, A. et al. IL-23-responsive innate lymphoid cells are increased in inflammatory bowel disease. J. Exp. Med. 208, 1127-1133 (2011).

6. Powell, N. et al. The transcription factor T-bet regulates intestinal inflammation mediated by interleukin-7 receptor $(+)$ innate lymphoid cells. Immunity 37, 674-684 (2012).

7. Cox, J.H. et al. Opposing consequences of IL-23 signaling mediated by innate and adaptive cells in chemically induced colitis in mice. Mucosal Immunol. 5, 99-109 (2012).

8. Zheng, Y. et al. Interleukin-22, a T(H)17 cytokine, mediates IL-23-induced dermal inflammation and acanthosis. Nature 445, 648-651 (2007).

9. Hue, S. et al. Interleukin-23 drives innate and T cell-mediated intestinal inflammation. J. Exp. Med. 203, 2473-2483 (2006).

10. Tait Wojno, E.D. \& Artis, D. Innate lymphoid cells: balancing immunity, inflammation, and tissue repair in the intestine. Cell Host Microbe 12 445-457 (2012).

11. Spits, H. \& Di Santo, J.P. The expanding family of innate lymphoid cells: regulators and effectors of immunity and tissue remodeling. Nat. Immunol. 12, 21-27 (2011).

12. Spits, H. \& Cupedo, T. Innate lymphoid cells: emerging insights in development, lineage relationships, and function. Annu. Rev. Immunol. 30 647-675 (2012).

13. Spits, H. et al. Innate lymphoid cells—a proposal for uniform nomenclature. Nat. Rev. Immunol. 13, 145-149 (2013).

14. Sun, Z. et al. Requirement for RORgamma in thymocyte survival and lymphoid organ development. Science 288, 2369-2373 (2000).

15. Mebius, R.E., Rennert, P. \& Weissman, I.L. Developing lymph nodes collect CD4 + CD3- LTbeta + cells that can differentiate to APC, NK cells, and follicular cells but not T or B cells. Immunity 7, 493-504 (1997).

16. Sawa, S. et al. Lineage relationship analysis of RORgammat + innate lymphoid cells. Science 330, 665-669 (2010).

17. Rankin, L.C. et al. The transcription factor T-bet is essential for the development of NKp46 + innate lymphocytes via the Notch pathway. Nat. Immunol. 14, 389-395 (2013).

18. van de Pavert, S.A. \& Mebius, R.E. New insights into the development of lymphoid tissues. Nat. Rev. Immunol. 10, 664-674 (2010).

19. Cupedo, T. Human lymph node development: an inflammatory interaction. Immunol. Lett. 138, 4-6 (2011).

20. Sonnenberg, G.F., Monticelli, L.A., Elloso, M.M., Fouser, L.A. \& Artis, D. $\mathrm{CD} 4(+)$ lymphoid tissue-inducer cells promote innate immunity in the gut. Immunity 34, 122-134 (2011).

21. Sanos, S.L. et al. RORgammat and commensal microflora are required for the differentiation of mucosal interleukin 22-producing NKp46 + cells. Nat. Immunol. 10, 83-91 (2009).

22. Sawa, S. et al. ROR gamma $t(+)$ innate lymphoid cells regulate intestinal homeostasis by integrating negative signals from the symbiotic microbiota. Nat. Immunol. 12, 320-326 (2011).

23. Satoh-Takayama, N. et al. Microbial flora drives interleukin 22 production in intestinal $\mathrm{NKp} 46(+)$ cells that provide innate mucosal immune defense. Immunity 29, 958-970 (2008).

24. Marodi, L. Innate cellular immune responses in newborns. Clin. Immunol. 118, 137-144 (2006).

25. Moens, E., Brouwer, M., Dimova, T., Goldman, M., Willems, F. \& Vermijlen, D. IL-23R and TCR signaling drives the generation of neonatal Vgamma9Vdelta2 $\mathrm{T}$ cells expressing high levels of cytotoxic mediators and producing IFN-gamma and IL-17. J. Leukoc. Biol. 89, 743-752 (2011).

26. Levy, O. Innate immunity of the newborn: basic mechanisms and clinical correlates. Nat. Rev. Immunol. 7, 379-390 (2007).

27. Kollmann, T.R. et al. Neonatal innate TLR-mediated responses are distinct from those of adults. J. Immunol. 183, 7150-7160 (2009).

28. Vanden Eijnden, S., Goriely, S., De Wit, D., Goldman, M. \& Willems, F. Preferential production of the IL-12(p40)/IL-23(p19) heterodimer by dendritic cells from human newborns. Eur. J. Immunol. 36, 21-26 (2006).
29. Willems, F., Vollstedt, S. \& Suter, M. Phenotype and function of neonatal DC. Eur. J. Immunol. 39, 26-35 (2009).

30. Vanden Eijnden, S., Goriely, S., De Wit, D., Willems, F. \& Goldman, M. IL-23 up-regulates IL-10 and induces IL-17 synthesis by polyclonally activated naive T cells in human. Eur. J. Immunol. 35, 469-475 (2005).

31. Sun, C.M., Fiette, L., Tanguy, M., Leclerc, C. \& Lo-Man, R. Ontogeny and innate properties of neonatal dendritic cells. Blood 102, 585-591 (2003).

32. Dakic, A. et al. Development of the dendritic cell system during mouse ontogeny. J. Immunol. 172, 1018-1027 (2004).

33. Parham, C. et al. A receptor for the heterodimeric cytokine $\mathrm{IL}-23$ is composed of IL-12Rbeta1 and a novel cytokine receptor subunit, IL-23R. J. Immunol. 168, 5699-5708 (2002).

34. Awasthi, A. et al. Cutting edge: IL-23 receptor gfp reporter mice reveal distinct populations of IL-17-producing cells. J. Immunol. 182, 5904-5908 (2009).

35. Pinto, D., Robine, S., Jaisser, F., El Marjou, F. \& Louvard, D. Regulatory sequences of the mouse villin gene that efficiently drive transgenic expression in immature and differentiated epithelial cells of small and large intestines. J. Biol. Chem. 274, 6476-6482 (1999).

36. Uhlig, H.H. et al. Differential activity of IL-12 and IL-23 in mucosal and systemic innate immune pathology. Immunity 25, 309-318 (2006).

37. Crellin, N.K., Trifari, S., Kaplan, C.D., Satoh-Takayama, N., Di Santo, J.P. \& Spits, H. Regulation of cytokine secretion in human CD127(+) LTi-like innate lymphoid cells by Toll-like receptor 2. Immunity 33, 752-764 (2010).

38. Mueller, S.N. et al. Regulation of homeostatic chemokine expression and cell trafficking during immune responses. Science 317, 670-674 (2007).

39. Marchesi, F. et al. CXCL13 expression in the gut promotes accumulation of IL-22-producing lymphoid tissue-inducer cells, and formation of isolated lymphoid follicles. Mucosal Immunol. 2, 486-494 (2009).

40. Mebius, R.E. Organogenesis of lymphoid tissues. Nat. Rev. Immunol. 3, 292-303 (2003).

41. Eberl, G., Marmon, S., Sunshine, M.J., Rennert, P.D., Choi, Y. \& Littman, D.R. An essential function for the nuclear receptor RORgamma(t) in the generation of fetal lymphoid tissue inducer cells. Nat. Immunol. 5, 64-73 (2004).

42. Vonarbourg, C. et al. Regulated expression of nuclear receptor RORgammat confers distinct functional fates to NK cell receptorexpressing RORgammat $(+)$ innate lymphocytes. Immunity 33, 736-751 (2010).

43. Lei, Z. et al. EpCAM contributes to formation of functional tight junction in the intestinal epithelium by recruiting claudin proteins. Dev. Biol. 371, 136-145 (2012).

44. Sonnenberg, G.F. et al. Innate lymphoid cells promote anatomical containment of lymphoid-resident commensal bacteria. Science 336, 1321-1325 (2012).

45. Philip, N.H. \& Artis, D. New friendships and old feuds: relationships between innate lymphoid cells and microbial communities. Immunol. Cell Biol. 91, 225-231 (2013)

46. Maloy, K.J., Salaun, L., Cahill, R., Dougan, G., Saunders, N.J. \& Powrie, F. $\mathrm{CD} 4+\mathrm{CD} 25+\mathrm{T}(\mathrm{R})$ cells suppress innate immune pathology through cytokine-dependent mechanisms. J. Exp. Med. 197, 111-119 (2003).

47. Coursodon-Boyiddle, C.F. et al. Pomegranate seed oil reduces intestinal damage in a rat model of necrotizing enterocolitis. Am. J. Physiol. Gastrointest. Liver Physiol. 303, G744-G751 (2012).

48. Fox, J.G., Ge, Z., Whary, M.T., Erdman, S.E. \& Horwitz, B.H. Helicobacter hepaticus infection in mice: models for understanding lower bowel inflammation and cancer. Mucosal Immunol. 4, 22-30 (2011).

49. Shang, L. et al. Toll-like receptor signaling in small intestinal epithelium promotes B-cell recruitment and IgA production in lamina propria. Gastroenterology 135, 529-538 (2008).

50. Caporaso, J.G. et al. QIIME allows analysis of high-throughput community sequencing data. Nat. Methods 7, 335-336 (2010).

51. Bongers, G. et al. Interplay of host microbiota, genetic perturbations, and inflammation promotes local development of intestinal neoplasms in mice. J. Exp. Med. 211, 457-472 (2014). 